\title{
Conditioned changes in the basal forebrain: Relations with learning-induced cortical plasticity
}

\author{
C. MAHO, B. HARS, J.-M. EDELINE, and E. HENNEVIN \\ Laboratoire de Neurobiologie de l'Apprentissage et de la Mémoire \\ Université Paris-Sud, Orsay, France
}

\begin{abstract}
Simultaneous recordings were performed in the auditory cortex and in the basal forebrain (BF) of rats subjected to habituation, conditioning (tone followed by a footshock), extinction, and reconditioning. Quantification of myographic activity from the neck muscles revealed behavioral conditioning in 10-20 trials. Short-latency, increased discharges of the BF neurons were observed within the first 5 conditioning trials, whereas tone-evoked responses above the level of the first habituation trials only started to occur between the 5 th and the 10 th trial in the auditory cortex. Increased discharges persisted in the $\mathrm{BF}$ during extinction; the cortical responses returned to their habituation level. Relative to conditioning, pseudoconditioning induced much smaller increased discharges in both structures. The role of the BF neurons in promoting learning-induced cortical plasticity is discussed in light of these results.
\end{abstract}

Over the last decade, a large amount of data has strongly suggested the role of acetylcholine ( $\mathrm{ACh}$ ) in cortical plasticity. In iontophoretic studies, it has been found that pairing a sensory stimulus with the application of $\mathrm{ACh}$ facilitates cortical responsiveness to that stimulus (Lamour, Dutar, Jobert, \& Dykes, 1988; Metherate, Tremblay, \& Dykes, 1987, 1988; Murphy \& Sillito, 1991; Sillito \& Kemp, 1983). The same types of facilitation have been observed when a sensory stimulus has been paired with a stimulation of the nucleus basalis magnocellular (NBM), which provides almost all the extrinsic cortical ACh (Edeline, Hars, Maho, \& Hennevin, 1994; Edeline, Maho, Hars, \& Hennevin, 1994; Hars, Maho, Edeline, \& Hennevin, 1993; Metherate \& Ashe, 1991; Rasmusson \& Dykes, 1988; Tremblay, Warren, \& Dykes, 1990). Conversely, iontophoretic application of atropine blocks the plasticity induced in the somatosensory cortex when stimulations of different vibrissae are paired (Delacour, Houcine, \& Costa, 1990). Also, lesion or inactivation of the NBM reduces the responses normally observed in the frontal cortex after a sensory stimulus has been paired with a stimulation of the medial forebrain bundle in urethane-anesthetized rats (Pirch, Corbus, Rigdon, \& Lyness, 1986; Rigdon \& Pirch, 1986).

On the other hand, an impressive amount of data has shown that behavioral training induces plasticity in the sensory neocortex (Diamond \& Weinberger, 1986; Jenkins, Merzenich, Ochs, Allard, \& Guic-Robles, 1990; Recanzone, Merzenich, Jenkins, Grajski, \& Dinse, 1992;

Correspondence may be addressed to E. Hennevin, NAM, URA 1491, Bat. 446 Université Paris-Sud, 91405 Orsay Cedex, France.
Recanzone, Schreiner, \& Merzenich, 1993). Learninginduced plasticity has been studied especially in the auditory cortex. In many species, under different protocols, the neuronal discharges evoked by a tone have increased when this tone was used as a conditioned stimulus (CS) signaling an appetitive or an aversive event used as unconditioned stimulus (US; for review, see Weinberger \& Diamond, 1987). Determination of the neuron's frequency receptive field before and after learning has shown that such increased evoked responses are highly selective for the CS (Bakin \& Weinberger, 1990; Edeline, Pham, \& Weinberger, 1993; Edeline \& Weinberger, 1993). Finally, both electrophysiological (Recanzone et al., 1993) and 2DG (Gonzalez-Lima \& Scheich, 1986; Scheich \& Simonis, 1991) data have revealed that these increased neuronal responses to the CS correspond to an enlarged cortical representation for the significant stimulus.

At the same time, recordings in primate NBM provided some evidences that certain neurons respond, with increased or decreased discharges, to the delivery (DeLong, 1971; Richardson \& DeLong, 1986) or to the sight (Mora, Rolls, \& Burton, 1976; Rolls, Sanghera, \& Roper-Hall, 1979) of a rewarding stimulus. They also respond to events preceding the occurrence of reward (Richardson \& DeLong, 1986; Travis \& Sparks, 1968; Wilson \& Rolls, 1990a, 1990b).

Altogether, these data have led some authors to propose that, during learning, increased release of $\mathrm{ACh}$ from the NBM neurons promotes the emergence of cortical plasticity (Ashe \& Weinberger, 1991; Richardson \& DeLong, 1991b). More precisely, to account for the learning-induced plasticity in the auditory cortex, it has been proposed that the NBM acts concomitantly with 
the tonotopic (MGv) and non-tonotopic (MGm) parts of the auditory thalamus, the former specifying the physical parameters of the stimulus, the latter specifying the behavioral significance of the stimulus (Weinberger et al., 1990). On the basis of the fact that ACh increases the membrane resistance, the cholinergic input from the NBM neurons is supposed to amplify the effect of the MGm input on the cortical cells, thereby producing a widespread enhancement of postsynaptic activation during learning trials.

Such a hypothesis has several implications concerning the sequence of events that should occur during learning. First, in order to promote associatively induced cortical plasticity, the population of NBM neurons has to exhibit, on the average, increased discharges at CS presentations. Indeed, if the NBM neurons show only tonic increases in spontaneous activity or respond only to US presentations, conditioning and pseudoconditioning should lead to similar effects in the sensory cortex. Second, the conditioned responses of the NBM neurons to the CS should occur rapidly in the course of learning, at least in the same number of trials as do the cortical conditioned responses. Last, given that the cortical evoked responses have been facilitated in iontophoretic studies when the cortical neurons are coactivated by ACh and by the sensory input (Metherate et al., 1987), one can wonder whether the latency of the NBM conditioned responses to the CS is short enough to allow such a cholinergic facilitation during learning.

In the present experiment, we examined to what extent the plasticity observed during learning in the auditory cortex is related to neuronal changes occurring in the NBM . A group of conditioned animals was submitted to habituation, conditioning (CS-US paired trials), extinction, and reconditioning. For a group of pseudoconditioned animals, explicitly unpaired CS and US presentations were delivered instead of the conditioning trials. Simultaneous recordings were performed in the auditory cortex (ACx) and in the basal forebrain (BF) area which projects to the temporal cortex. Determination for each structure of (1) the number of trials required for the emergence of conditioned changes and (2) the latency of the conditioned changes after tone onset should bring some light to the evaluation of whether and when during learning, and during a single learning trial, the BF neurons can promote cortical plasticity.

\section{METHOD}

\section{Subjects}

The subjects were 16 male Wistar rats weighing $290-400 \mathrm{~g}$ at the time of surgery. The animals, housed in individual cages with continual access to food and water, were placed under a 12:12-h light:dark cycle. Behavioral training took place during the light period.

\section{Electrode Implantation}

The recording electrodes were stereotaxically implanted while the animals were under deep anesthesia (pentobarbital, $60 \mathrm{mg} / \mathrm{kg}$ ).
The electrodes were Teflon-insulated Tungsten wires $(50 \mu \mathrm{m}, \mathrm{A}-\mathrm{M}$ System); two of them were inserted into a stainless steel microtube ( $300 \mu \mathrm{m}$ o.d.), the non-insulated extremity of which was used for differential recordings. The electrodes, connected to multichannel miniature sockets, were slowly lowered in both structures under electrophysiological control. For the auditory cortex, a large opening centered $4.5 \mathrm{~mm}$ posterior to bregma was made in the temporal bone and the final adjustment of the electrodes was made to optimize the responses to $6-$ to $10-\mathrm{kHz}$ tones delivered via hollow ear bars. The coordinates for the recording elect rodes in the BF were: $1.8-2.8$ posterior and $3.0-3.6$ lateral to bregma; $7-7.5$ below the dura. These coordinates were selected for two reasons: first, anatomical data reported that the BF neurons projecting to the temporal cortex are located in the caudal aspect of the NBM (Bigl, Woolf, \& Butcher, 1982; Lamour, Dutar, \& Jobert, 1982; Luiten, Gaykema, Traber, \& Spencer, 1987; Moriizumi \& Hattori, 1992; Rye, Wainer, Mesulam, Mufson, \& Saper, 1984; Saper, 1984). Second, our previous studies (Edeline, Hars, et al., 1994; Edeline, Maho, et al., 1994; Hars et al., 1993) have shown that stimulation of BF neurons at these locations enhances tone-evoked response in the ipsilateral auditory cortex.

Two extradural cortical electrodes, made of small silver spheres, were placed along the interhemispheric suture with a large fronto-parictal derivation for the recording of electrocorticographic (EEG) activity. The electromyographic (EMG) activity was recorded from two silver wires inserted in the dorsal neck muscles. A silver sphere placed between the dura and the parietal bone was used as the ground.

The three miniature sockets were fixed to the skull with dental acrylic cement. Local antiseptics (Exoseptoplix) were liberally administered in the wound at the end of the surgery. One week of recovery was allowed before the start of the experiment.

\section{Apparatus and Recording Procedures}

The experimental box $(25 \times 25 \times 50 \mathrm{~cm})$ was placed in a soundattenuating chamber; each had a transparent front door that allowed visual control of the animal. The top of the experimental box was equipped with a loudspeaker $(5 \mathrm{~cm}$ in diameter, bandpass 20-20000 Hz). Counterbalanced cables connected to the animal's head were relayed at the top of the box through a multichannel rotating connector. The grid floor of the box was made of stainless steel rods, $0.5 \mathrm{~cm}$ in diameter, that were spaced $1.5 \mathrm{~cm}$ center to center. The scrambled electrical footshock used as the US was delivered through the grid floor via an isolation unit placed on the side of the experimental box.

The neuronal activity was recorded through subminiature operational amplifiers (surface mount package, Texas Instruments TL074, input $15 \mathrm{pA}$ ) located on the animal's head at the extremity of the recording cables. The activity was amplified (Grass, Model P511K, gain 10,000), filtered $(500-10000 \mathrm{~Hz})$ and displayed on an oscilloscope. The signal was sent to voltage window discriminators to select the largest spikes (signal to noise at least 2/1). The EMG activity was fed to a preamplifier (bandpass $1-75 \mathrm{~Hz}$ ) of a Grass polygraph and sent to a window discriminator, the triggering level of which was adjusted to provide about 10-20 counts per seconds when the animal was motionless.

The output pulses of all the triggers were stored on each trial by a 386-PC-based microcomputer during the 1 -sec pretone and the $2 \mathrm{sec}$ of tone. The time of occurrence of each pulse was dated with a precision of $50 \mu \mathrm{sec}$ by the acquisition board, and home-made software provided at each trial on-line rasters for four channels of neural activity (two from the auditory cortex, two from the basal forebrain) and for the EMG activity. Off-line analysis allowed construction of standard peristimulus time histograms using any selected time bin, and quantification of the tone-evoked responses on each channel by selection of temporal windows after tone onset. A home-made electronic circuit grounded the input of the 
preamplifiers from $1 \mathrm{msec}$ before until $1 \mathrm{msec}$ after the delivery of footshock, to avoid its saturation.

\section{Experimental Protocol}

After 1 day of familiarization with the experimental cage and the recording cables, the animals were trained on 3 successive days. On each day, the intertrial interval was about $3 \mathrm{~min}$ (range, $1-5$ ); all trials were delivered while the animals were motionless. During each daily session, the EEG and the EMG were continuously monitored on a polygraph.

On Day 1, an habituation phase was followed by conditioning: Twenty tone-alone presentations $(6$ or $10 \mathrm{kHz}$, about $70 \mathrm{~dB}$ at the center of the cage, $2 \mathrm{sec}$ in duration) were followed by 20 conditioning trials during which the footshock $(0.2-0.3 \mathrm{~mA}, 500 \mathrm{msec})$ was delivered at the end of the tone.

On Day 2, conditioning was followed by an extinction phase: Twenty conditioning trials (CS-US pairing trials) were followed by 20 extinction trials during which the tone was delivered alone.

On Day 3, the extinction phase was followed by reconditioning: Twenty tone-alone presentations were followed by $20 \mathrm{CS}-\mathrm{US}$ pairing trials.

The pseudoconditioned animals underwent the same phases, except that explicitly unpaired presentations of tone and footshock were delivered instead of the CS-US pairing trials.

\section{Data Analyses}

The off-line analyses focused on the neuronal activity recorded during the $80 \mathrm{msec}$ following tone onset, since this period included the whole cortical evoked response and the maximal conditioned response for the BF activity. As specified in the Results section, the tone-evoked responses were analyzed by using different time resolutions after tone onset $(10,20,40 \mathrm{msec})$; and blocks of 5 or 10 trials were used to average the data during each phase of the protocol.

Statistical comparisons were carried out with analysis of variance (VAR3 software package; Lebeaux, Lépine, \& Rouanet, 1975) performed on the averaged value obtained at a given block of trials, with each recorded electrode as a subject factor. First, for each group and each structure, comparisons were performed between the evoked responses obtained at the different phases of the protocol. Second, for each structure, the evoked responses obtained in the conditioned and pseudoconditioned animals were compared in order to evaluate the associative nature of the changes induced by conditioning. Third, between-structure comparisons were performed to determine whether the different phases of the protocol differentially affected neuronal responsiveness in the $\mathrm{ACx}$ and in the BF.

The output pulses generated by triggering the EMG activity were analyzed in the same way as were the neuronal data, except that in the statistical comparisons each animal was used as a subject factor.

\section{Determination of EEG Desynchmonization by \\ BF Stimulation and Histology}

In an attempt to evaluate the reliability of our electrode placement in the NBM area, electrical stimulations (.1-msec pulses, $100 \mathrm{~Hz}, 300 \mathrm{msec}$ ) were delivered through the $\mathrm{BF}$ recording electrodes 2-3 days after the end of training. Indeed, stimulation of the NBM is known to induce EEG desynchronization (Belardetti, Borgia, \& Mancia, 1977; Casamenti, Deffenu, Abbamondi, \& Pepeu, 1986; Metherate, Cox, \& Ashe, 1992). The animals were placed in the experimental box, and the EEG and EMG were continuously monitored on a polygraph. When the animals were engaged in consistent slow-wave sleep phases, stimulations were delivered via a constant-current stimulation unit through the two BF recording electrodes to determine the threshold for EEG desynchronization.

After determination of this threshold, the animals were perfused (intracardiac perfusion) under deep pentobarbital anesthesia
$(120 \mathrm{mg} / \mathrm{kg}$ ) with $0.9 \%$ saline followed by $10 \%$ formalin. The brains were kept in 10\% formalin for 2 weeks; then they were frozen, sliced at $60 \mu \mathrm{m}$, and stained with cresyl violet for Nissl preparation.

\section{RESULTS}

The results presented here were obtained from 16 subjects (conditioning, $n=8$; pseudoconditioning, $n=8$ ) that yielded data from 26 recording sites in the auditory cortex (conditioning, $n=13$; pseudoconditioning, $n=$ 13 ) and 26 recording sites in the basal forebrain (conditioning, $n=13$; pseudoconditioning, $n=13$ ). All of the cortical recordings exhibited clear short-latency excitatory responses to tone presentations. The recording sites in the BF were located in the dorsal aspect of the substantia innominata or at the boundary between the substantia innominata and the globus pallidus - that is, in the region considered as the caudal aspect of the rat NBM (see Figure 1). For all these sites, a clear desynchronization of the neocortical EEG was observed when BF stimulation was applied during slow-wave sleep at the end of the experiment (mean arousal threshold was $63 \pm 8 \mu \mathrm{A}$ for the conditioned group and $58 \pm 10 \mu \mathrm{A}$ for the pseudoconditioned group).

First, we will present the changes in EMG reactivity to the tone in order to determine whether conditioned behavioral responses developed in the course of the experiment. Second, we will compare the changes of cellular activity observed in the conditioned and pseudoconditioned groups, in order to assess the associative nature of the effects induced by conditioning in the $\mathrm{ACx}$ and in the BF. For these comparisons, we considered the

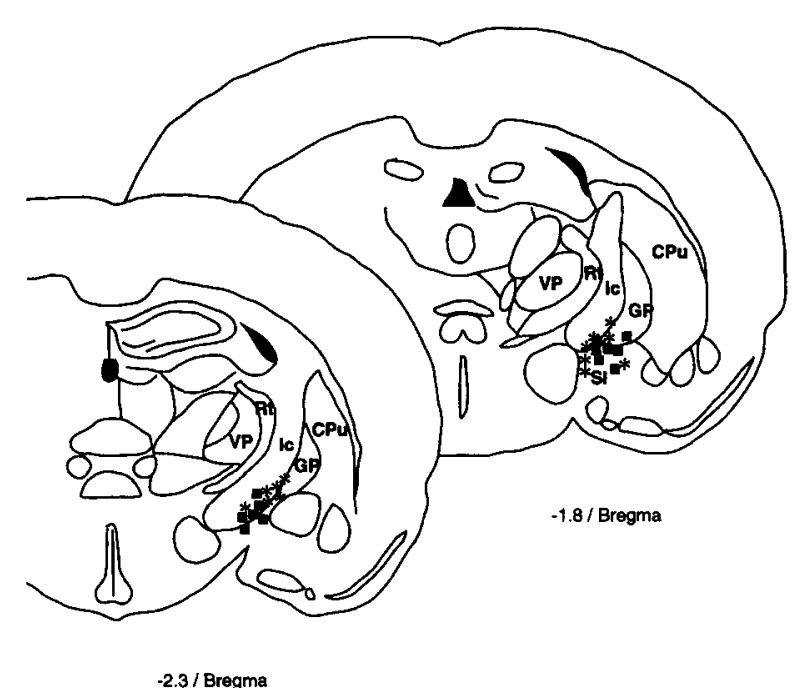

Figure 1. Outlines showing the placements of the recording electrodes in the basal forebrain for the conditioned (black squares) and pseudoconditioned (asterisks) animals. At the two anteriorities, the anatomical limits between structures were redrawn from Paxinos and Watson's (1986) atlas. CPu, caudate-putamen; GP, globus pallidus; ic, internal capsule; Rt, reticular thalamic nucleus; SI, substantia innominata; VP, ventral posterior thalamic nucleus. 
responses evoked during the whole period of $80 \mathrm{msec}$ following tone onset, and we grouped the trials by blocks of 10 trials. Last, we will analyze in more detail the neuronal changes observed in the conditioned group, in order to compare the characteristics and the kinetics of the learning-induced changes in the $\mathrm{ACx}$ and in the $\mathrm{BF}$.

\section{Behavioral Data}

During the habituation trials, neck-muscle EMG activity was similar in both groups $[F(1,14)<1$, whatever the period of time analyzed after tone onset].

If we consider, first, the EMG responses observed during the first $80 \mathrm{msec}$ of tone presentation - that is, the period during which cellular responses were analyzedno significant changes over the experiment [across the 12 successive blocks of 10 trials, $F(11,77)=1.420$, n.s., and $F(11,77)<1$, for, respectively, the conditioned and the pseudoconditioned groups] and no difference between the two groups $[F(11,154)<1]$ were observed. Since these early EMG increases were not different between habituation and conditioning $[F(1,7)=2.270$, n.s.], between habituation and pseudoconditioning $[F(1,7)=3.175$, n.s. $]$, between conditioning and extinction $[F(1,7)<1]$, between conditioning and pseudoconditioning $[F(1,14)<1]$, they likely reflected unconditioned reactions to tone onset.

On the other hand, conditioned motor responses to the tone appeared later after tone onset and were detected when EMG activity was analyzed during the whole $1 \mathrm{st} \mathrm{sec}$ of tone. EMG reactivity to the tone was significantly modified over the experiment in the conditioned animals $[F(11,77)=4.824, p<.001]$, but not in the pseudoconditioned animals $[F(11,77)=1.347$, n.s.]. Compared with the habituation level, the increases of EMG activity observed in the conditioned group during training, extinction, and retraining were larger than those observed in the pseudoconditioned group $[F(1,14)=$ $5.151, p<.05]$. Indeed, the EMG responses were enhanced during the conditioning trials above the habituation level $[F(1,7)=12.974, p<.01]$. This increased response became larger over the tone duration: it was already present during the first $500 \mathrm{msec}$ of tone $[F(1,7)=$ $6.933, p<.05]$, but it was more pronounced during the following $500 \mathrm{msec}[F(1,7)=16.251, p<.005]$. It developed in the course of conditioning: whereas it was not significant at the first 10 -trial block of conditioning $[F(1,7)<1]$, it was significant at the three subsequent blocks $[p<.025$ or less]. This conditioned response was attenuated during the extinction trials, but it did not totally extinguish: even during the last 10 trials of the extinction procedure, the EMG responses remained above the habituation level $[F(1,7)=15.696, p<.01]$. Increases in EMG responses to the tone were also observed in the pseudoconditioned group. However, unlike those in the conditioned group, they never significantly differed from the habituation level [higher $F$ value: $F(1,7)=2.964$, n.s., for the third 10-trial block of pseudoconditioning]. Figure 2 summarizes the changes of EMG responses to the tone observed in the two groups.

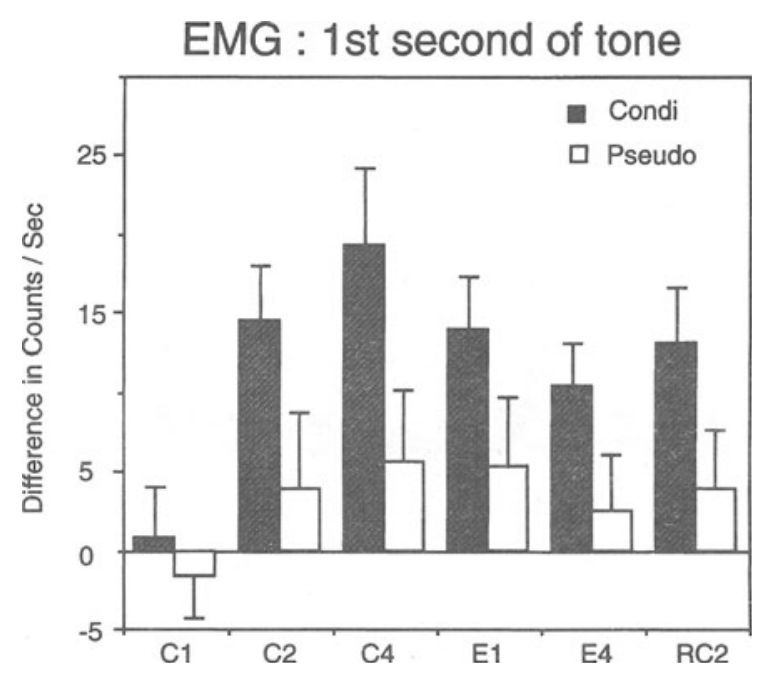

Figure 2. Conditioning of the EMG response. Each bar represents mean evoked EMG activity ( $\triangle S E M$ ) recorded during the 1st sec of tone at different blocks of 10 trials after subtraction of mean evoked EMG activity recorded during habituation. $\mathrm{C1}, \mathrm{C} 2$, and $\mathrm{C} 4$ represent, respectively, Trials 1-10, 11-20, and 31-40 of training; E1 and E4, Trials 1-10 and 31-40 of extinction; and RC2, Trials 11-20 of retraining. Note for the conditioned group ( $n=8$; hatched bars) the large increase of EMG response which appeared at the second block of 10 conditioning trials $(\mathrm{C} 2)$. Note also that the pseudoconditioned animals ( $n=8$; white bars) exhibited much smaller increases in EMG activity (which in fact were never significantly above the habituation level).

Thus, pairing the tone with footshock induced conditioned behavioral responses to the tone, as is evidenced by increased myographic responses which developed in the course of conditioning and which reached their maximal amplitude several hundred of milliseconds after tone onset.

\section{Neuronal Responses to Tone in Auditory Cortex}

In the conditioned group, the "on" excitatory response occurring within the first $80 \mathrm{msec}$ following tone onset showed marked changes over the successive phases of the experiment [across the 12 blocks of 10 trials, $F(11,132)=5.869, p<.001]$. These changes were not due to changes in spontaneous pretone activity, which was not modified over the experiment $[F(11,132)<1]$. First, as can be seen in Figure 3, the tone-evoked discharges were higher during the 40 trials of conditioning than they were during the 20 trials of habituation $[F(1,12)=28.859, p<.001]$. This increase was observed for each of the four blocks of conditioning $[p<$ .005 or less], but it was higher for the fourth block than for the first one $[F(1,12)=8.047, p<.025]$. Second, this enhanced response progressively diminished over the extinction procedure. During the last 10 trials of extinction, the evoked responses were lower than they were during the last 10 trials of conditioning $[F(1,12)=$ $19.272, p<.001]$, and they no longer differed from the habituation level $[F(1,12)=1.812$, n.s. $]$. Third, the toneevoked responses increased again during recondition- 


\section{Auditory Cortex}
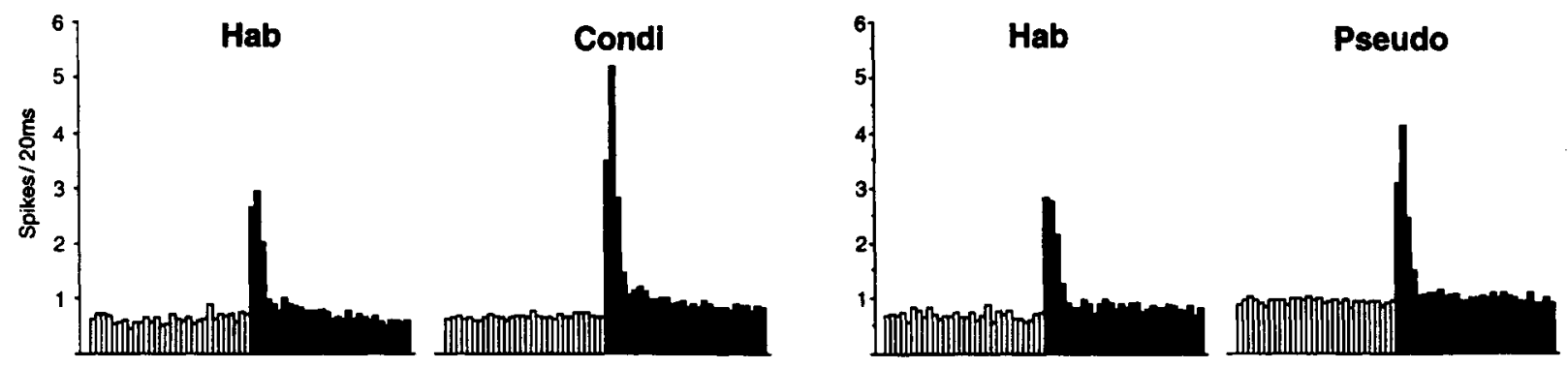

\section{Basal Forebrain}
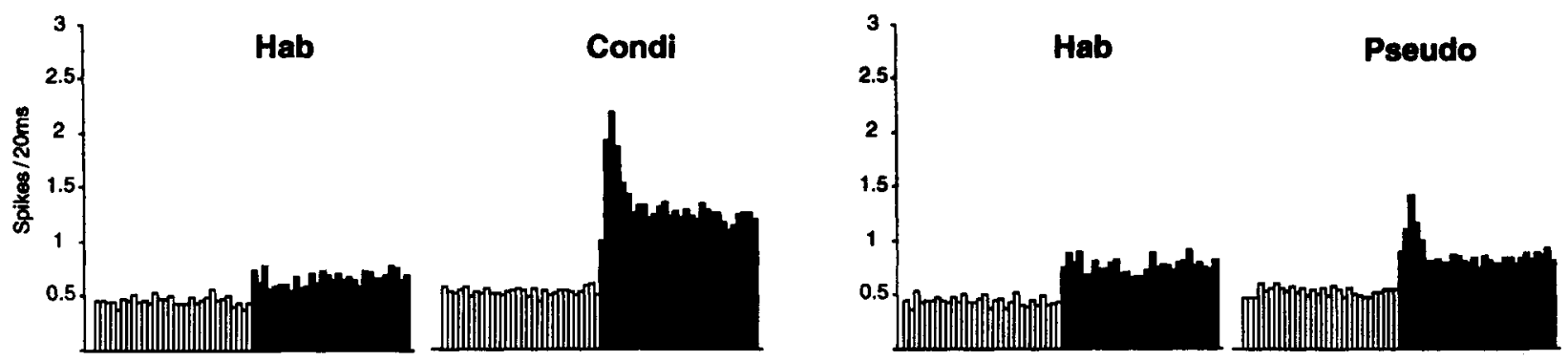

Figure 3. Cellular changes induced by training for the conditioned (left) and pseudoconditioned (right) groups. Each histogram represents the mean number of spikes per bin of 20 msec during the 600 msec preceding (open bars) and the 600 msec following (dark bars) tone onset. The histograms are from the 20 trials of habituation (Hab) and the 40 trials of conditioning (Condi) or of pseudoconditioning (Pseudo). Note the increase of the "on" tone-evoked response in auditory cortex and the emergence of a large, sustained response in the basal forebrain during conditioning. Note also that in both structures pseudoconditioning induced much smaller changes than conditioning did.

ing, where they were higher than during the last 10 trials of extinction $[F(1,12)=10.268, p<.01]$ and higher than during habituation $[F(1,12)=5.228, p<.05]$.

In the pseudoconditioned group, contrary to what was observed in the conditioned group, spontaneous pretone activity was modified over the experiment $[F(11,132)=$ $7.509, p<.001]$ : it increased during pseudoconditioning and remained higher during extinction and retraining. The "on" tone-evoked responses were also affected $[F(11,132)=2.673, p<.01]$. They were increased above the habituation level during pseudoconditioning $[F(1,12)=7.311, p<.025]$. Increased responses appeared in the third and fourth blocks [respectively, $p<$ .01 , and $p<.025]$, whereas they did not exist in the first two blocks [respectively, $F(1,12)<1$, and $F(1,12)=$ 1.240, n.s.]. The responses tended to be lower at the end of the extinction procedure than they were at the end of pseudoconditioning $[F(1,12)=4.265, p<.10]$. During retraining, although the responses tended to increase again, they significantly differed neither from those observed at the end of extinction $[F(1,12)=2.472$, n.s. $]$ nor from those observed during habituation $[F(1,12)=$ 2.313, n.s.].

The differential effects of the conditioning and pseudoconditioning procedures were further confirmed by between-group comparisons. The tone-evoked responses were similar in the two groups during the 20 habituation trials $[F(1,24)<1]$, and they showed comparable decreases between the first 10 and the last 10 trials of habituation $[F(1,24)=1.491$, n.s.]. However, there was a significant interaction $[F(1,24)=9.201, p<.01]$ between the factors of group and treatment trial (the 20 habituation trials vs. the $\mathbf{4 0}$ subsequent trials), indicating that the enhancement of the tone-evoked responses induced by conditioning was larger than that induced by pseudoconditioning. The two groups no longer differed during the 40 extinction trials - which is not surprising, given the strong reduction of the responses exhibited by the conditioned animals during the extinction procedure. Still, compared with the response level during the last 10 trials of extinction, the enhancement of the evoked responses induced by the retraining procedure tended to be higher in the conditioned group than in the pseudoconditioned group $[F(1,24)=2.941, p<.10]$. Figure 4A illustrates the changes of cortical evoked responses exhibited by the conditioned and pseudoconditioned animals during training, extinction, and retraining.

Thus, pairing the tone with footshock resulted in enhanced responses to the tone in the auditory cortex. These conditioned responses demonstrated extinction 

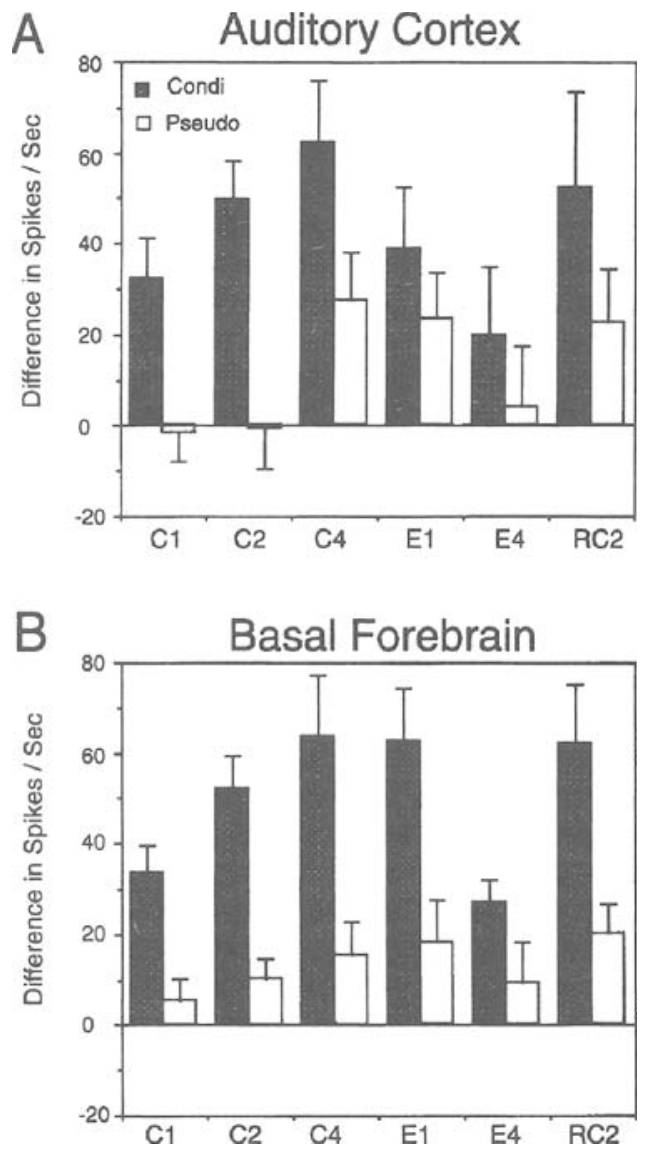

Figure 4. Comparison between changes induced by conditioning (hatched bars) and by pseudoconditioning (white bars) in auditory cortex and basal forebrain. For auditory cortex $(n=13$ in each group) and basal forebrain ( $n=13$ in each group), each bar represents the mean tone-evoked response $( \pm S E M)$ recorded during the first 80 msec of tone, after subtraction of the evoked response obtained during habituation. Same conventions as in Figure 2. Note that in both structures, pseudoconditioning induced smaller changes compared with the large enhancement induced by conditioning.

and reconditioning. Increased tone-evoked responses were also observed when unpaired presentations of tone and footshock were given; but they were significantly smaller than those induced by conditioning, and they were accompanied by increased spontaneous pretone activity.

\section{Neuronal Responses to Tone in Basal Forebrain}

Tone presentation increased BF neuronal discharges above the pretone level. The evoked discharges occurring in the first $80 \mathrm{msec}$ of tone changed over the experiment in both groups $[F(11,132)=23.788, p<.001$, and $F(11,132)=13.655, p<.001$, for, respectively, the conditioned and the pseudoconditioned groups]. But these changes were significantly different in the two groups $[F(11,264)=4.799, p<.001]$.

In the conditioned group, the spontaneous pretone activity was not modified over the experiment $[F(11,132)<$ 1]. During conditioning, large and sustained increases in firing rate occurred at CS presentations (see Figure 3). The discharges evoked during the first $80 \mathrm{msec}$ of tone were much higher than they were during habituation $[F(1,12)=33.277, p<.001]$. This increased responsiveness was observed for each block of 10 conditioning trials (in each case, $p<.001$ ). It was higher for the fourth block than for the first one $[F(1,12)=26.919, p<.001]$. Increased evoked discharges persisted during the extinction trials: they remained higher during the last 10 trials of extinction than they were during habituation $[F(1,12)=$ $32.603, p<.001]$. Nonetheless, they showed a progressive reduction in the course of the extinction procedure: the responses observed during the last 10 extinction trials were lower than those observed during the last 10 conditioning trials $[F(1,12)=7.683, p<.025]$. During reconditioning, the evoked responses increased again: they were higher than during the last 10 trials of extinction $[F(1,12)=12.524, p<.005]$.

In the pseudoconditioned group, spontaneous pretone activity showed a significant increase in the course of the experiment $[F(11,132)=2.195, p<.025]$. The toneevoked discharges also increased above the habituation level during pseudoconditioning $[F(1,12)=5.21, p<$ $.05]$. This increase was not present in the first 10-trial block $[F(1,12)=1.049$, n.s. $]$, but it was observed in the three subsequent blocks [respectively, $p<.05, p<.025$, and $p<.10]$. The evoked discharges were lower at the end of the extinction procedure than they were at the end of pseudoconditioning $[F(1,12)=5.260, p<.05]$. They tended to increase again during the retraining trials but not sufficiently to differ from those observed during the last 10 trials of extinction $[F(1,12)=1.921$, n.s.].

The conditioning and pseudoconditioning procedures differentially affected the tone-evoked discharges in the BF, as revealed by between-group comparisons. Reactivity to the tone was comparable in the two groups during the 20 habituation trials $[F(1,24)=2.446$, n.s. $]$, and it developed similar changes between the first 10 and the last 10 trials of habituation $[F(1,24)=1.007$, n.s.]. But the enhancement above the habituation level was higher in the conditioned group than it was in the pseudoconditioned group during training $[F(1,24)=9.201, p<$ $.01]$, extinction $[F(1,24)=12.394, p<.005]$, and retraining $[F(1,24)=11.346, p<.005]$. During extinction, the conditioned animals exhibited a stronger reduction of the evoked responses than did the pseudoconditioned animals, as was revealed by a significant interaction $[F(1,24)=4.475, p<.05]$ between the factors of group and treatment trial (the last 10 trials of extinction vs. the last 10 trials of training). During retraining, the conditioned animals exhibited a larger enhancement of the evoked responses than did the pseudoconditioned animals $[F(1,24)=4.899, p<.05$, when the retraining trials were compared with the last 10 trials of extinction]. Figure $4 \mathrm{~B}$ shows the changes of tone-evoked responses in the conditioned and pseudoconditioned groups during training, extinction, and retraining.

Thus, pairing the tone with footshock induced enhanced responsiveness to the tone in the BF. The condi- 
tioned responses demonstrated extinction and reconditioning. A much smaller increase, accompanied by increased spontaneous pretone activity, was observed when unpaired presentations of tone and footshock were given.

\section{Comparison of Changes in Responsiveness to Tone in Auditory Cortex and in Basal Forebrain}

We will successively describe the changes of responsiveness to the tone observed in the conditioned animals during habituation, conditioning, and extinction. Note again that these changes were not the consequence of changes in spontaneous pretone activity, which was never modified in the conditioned group either in the $\mathrm{ACx}$ or in the BF. In order to compare the rapidity with which responsiveness to the tone was modified in the course of each experimental phase in the $\mathrm{ACx}$ and in the $\mathrm{BF}$, we grouped the trials by blocks of five trials. In order to compare the latency with which changes of evoked discharges occurred after tone onset in the $\mathrm{ACx}$ and in the $\mathrm{BF}$, we divided the first $80 \mathrm{msec}$ of tone presentation into bins of $10 \mathrm{msec}$.

Habituation. The cortical responses evoked by the tone in the $80 \mathrm{msec}$ following tone onset decreased across the four blocks of habituation trials $[F(3,36)=$ $4.580, p<.01]$. As shown in Figure 5, they were lower in the fourth block than in the first one $[F(1,12)=$ $6.884, p<.025]$.
The sustained increase of BF activity elicited by tone presentation diminished in the course of habituation (see Figure 5). However, the discharges occurring in $80 \mathrm{msec}$ after tone onset did not show significant changes across the four blocks of habituation trials $[F(3,36)=1.303$, n.s.], although they tended to be lower in the fourth block than they were in the first one $[F(1,12)=3.196, p<.10]$.

Thus, repetitive presentations of the tone induced decreased responsiveness to the tone in both structures. However, this reduction across trials was more pronounced in the $\mathrm{ACx}$ than in the BF, especially when we compared the changes of the evoked discharges occurring in the first $40 \mathrm{msec}$ of tone $[F(3,72)=4.246, p<$ $.01]$. There was no significant difference between the two structures for the subsequent $40 \mathrm{msec}[F(3,72)=$ 1.434, n.s.].

Conditioning: Time course of conditioned changes after tone onset. A 1-msec bin analysis revealed that cortical neurons responded to tone with a mean latency of 9-10 msec, whereas the BF neurons responded with a mean latency of $14-15 \mathrm{msec}$. No change in latency was detected during conditioning either in the $\mathrm{ACx}$ or in the $\mathrm{BF}$.

The learning-induced increase in evoked discharges was manifested earlier after tone onset in the ACx than in the BF. First, in the first $20 \mathrm{msec}$ of tone, the cortical discharges increased over the eight blocks of conditioning trials $[F(7,84)=2.475, p<.025]$, being higher in the last block than in the first one $[F(1,12)=6.346, p<$

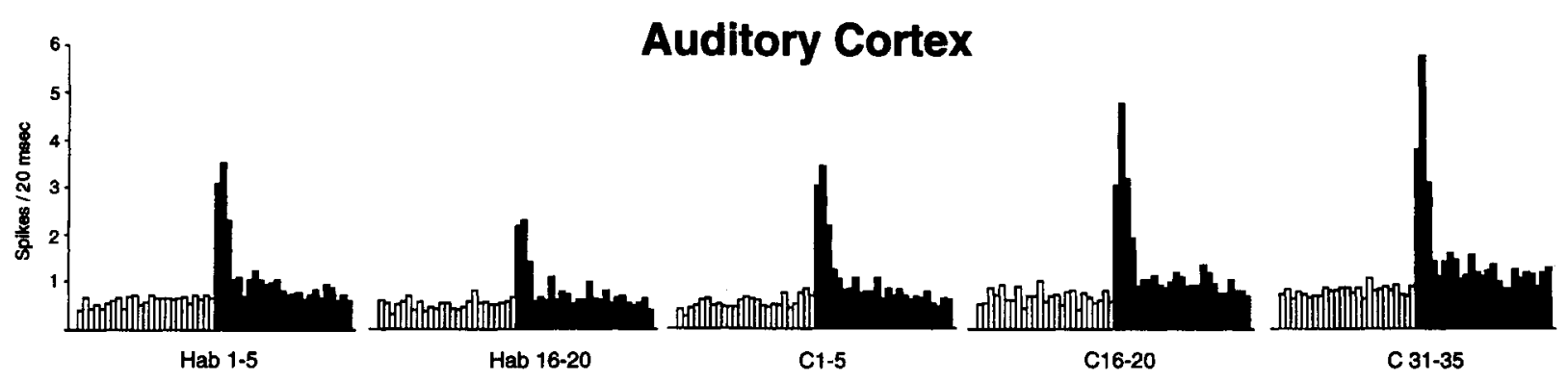

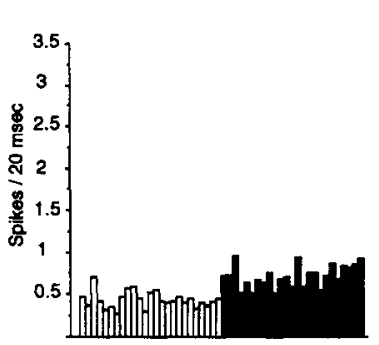

Hab 1-5

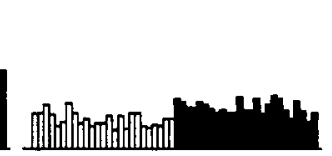

Hab $16-20$

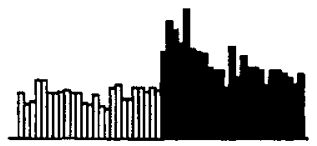

C1-5

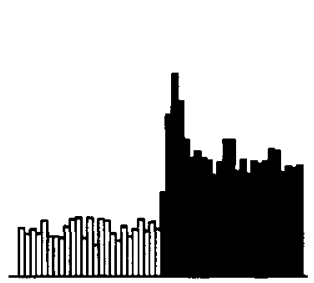

C16-20

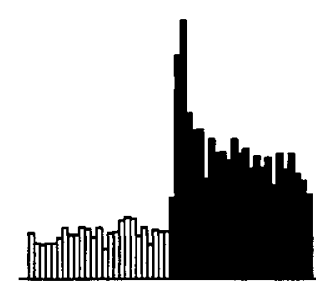

C 31-35

Figure 5. Habituation and conditioning of the tone evoked responses in auditory cortex and basal forebrain for the conditioned group. Each histogram represents the mean number of spikes per bin of 20 msec during the 500 msec preceding (open bars) and the 500 msec following (dark bars) tone onset. The histograms are from the first 5 and the last 5 trials of habituation (respectively, Hab 1-5 and Hab 16-20), and from Trials 1-5, 16-20, and 31-35 of conditioning (respectively, C1-5, C16-20, and C31-35). Note the decrement of the evoked responses in both structures between Hab 1-5 and Hab 16-20. Note also that as early as the first block of 5 conditioning trials (C1-5), the response evoked in the basal forebrain was above the level of the first trials of habituation, whereas the cortical response only recovered the same level as at the beginning of habituation. 
$.05]$. These increases occurred during the second bin of $10 \mathrm{msec}$ following tone onset $[F(7,84)=2.598, p<$ $.025]$; the first bin of $10 \mathrm{msec}$ was not affected $[F(7,84)<1]$. In contrast, the BF discharges evoked in the first 20 msec of tone showed no significant changes over conditioning $[F(7,84)<1]$, being comparable in the first and last blocks $[F(1,12)<1]$. Even if they tended to be higher during conditioning than at the end of habituation $[F(1,12)=4.450, p<.10]$, they were less enhanced than the cortical discharges were $[F(1,24)=$ $8.732, p<.01]$. Second, in the subsequent $20 \mathrm{msec}$ of tone presentation, the evoked discharges continued to be strongly increased in the $\mathrm{ACx}$ [over conditioning, $F(7,84)=4.713, p<.001$; for the comparison between the first and the last block, $F(1,12)=27.605, p<.001]$. Those in the BF also increased [respectively, $F(7,84)=$ $3.047, p<.01$, and $F(1,12)=6.253, p<.05]$, but less than they did in the ACx [respectively, $F(7,168)=$ $2.498, p<.025$, and $F(1,24)=12.226, p<.005$ ]. As a consequence, with regard to the first $40 \mathrm{msec}$ of tone, the enhancement of the evoked responses was significantly larger in the $\mathrm{ACx}$ than it was in the $\mathrm{BF}$.

The reverse was observed for the $40-80 \mathrm{msec}$ following tone onset. Even if the cortical discharges showed a slight increase over the eight blocks of conditioning $[F(7,84)=$ $2.416, p<.05]$, they did not significantly differ between the first and the last block $[F(1,12)<1]$. In contrast, the $\mathrm{BF}$ discharges exhibited marked increase over conditioning $[F(7,84)=4.965, p<.001]$, and they were higher in the last block than in the first one $[F(1,12)=11.946$, $p<.005]$. Between-structure comparisons indicated a larger enhancement of discharges in the BF than in the ACx [over conditioning, $F(7,168)=2.431, p<.025$; and for the comparison between the first and the last block, $F(1,24)=7.740, p<.025]$.

The finding that the conditioned changes occurred at a shorter latency after tone onset in the $\mathrm{ACx}$ than in the BF was corroborated by comparing the time course of the increase in discharges above the habituation level in the two structures. For each electrode, the mean evoked response obtained during the 20 habituation trials was subtracted from that obtained during the last 20 conditioning trials, with the temporal resolution of $10 \mathrm{msec}$. As can be seen in Figure 6, the learning-induced increase started earlier and ended earlier in the $\mathrm{ACx}$ than in the BF.

Thus, conditioned increases in tone-evoked discharges were manifested with a shorter latency after tone onset in the ACx than in the BF: they were more pronounced during the first $40 \mathrm{msec}$ of tone in the $\mathrm{ACx}$, whereas they were more pronounced in the subsequent $40 \mathrm{msec}$ in the BF.

Rapidity of development of conditioned responses in the course of conditioning. We studied at which fivetrial block of conditioning increased discharges to the tone appeared in the ACx and in the BF. Since the responses evoked by the tone in the two structures did not demonstrate the same degree of decrement across the habituation trials, we compared the responses observed
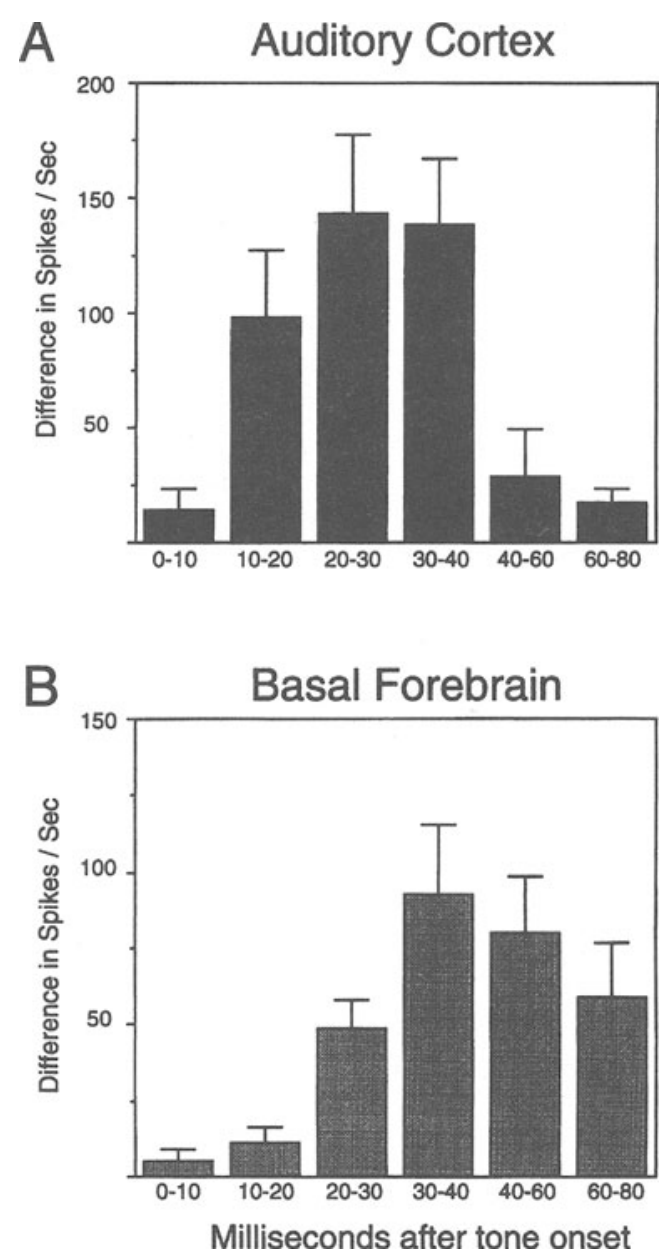

Figure 6. Time course of the conditioned changes after tone onset. For each recording and each period of analysis, the mean tone-evoked response obtained during the 20 trials of habituation was subtracted from the response obtained at the last 20 trials of conditioning. The resulting values were averaged across recordings and represented $\pm S E M$. Increased reactivity was analyzed by using 10-msec resolution for the first $\mathbf{4 0} \mathrm{msec}$ of tone, 20-msec resolution for the following $40 \mathrm{msec}$. Note that the conditioned increased response was prominent from 10 to $40 \mathrm{msec}$ after tone onset in the auditory cortex, while it was from 20 to 80 msec in the basal forebrain.

during conditioning with those observed during both the first and the last five-trial block of habituation. As can be seen in Figure 5, as early as the first five trials of conditioning, both the $\mathrm{ACx}$ and the $\mathrm{BF}$ discharges occurring in the first $80 \mathrm{msec}$ of tone were higher than those obtained at the end of habituation $[F(1,12)=23.936, p<$ .001 , and $F(1,12)=14.980, p<.005$, for, respectively, the $\mathrm{ACx}$ and the $\mathrm{BF}]$. They remained increased in the subsequent seven blocks of conditioning trials [for the $\mathrm{ACx}$, all $p \mathrm{~s}<.001$; for the $\mathrm{BF}$, all $p \mathrm{~s}<.005]$. On the other hand, when compared with those observed in the first five trials of habituation, the tone-evoked discharges observed during the first five trials of conditioning showed no enhancement in the $\mathrm{ACx}[F(1,12)<1]$, whereas they were strongly increased in the $\mathrm{BF}[F(1,12)=12.284$, 
$p<.005]$. Increased cortical responses above the level of the first habituation trials began to appear in the second block of conditioning trials $[F(1,12)=3.349, p<.10]$ and were maintained in the subsequent ones $[p<.10$ or $p<.05$, depending on the conditioning block]. In the $\mathrm{BF}$, the evoked discharges were much higher in each block of conditioning than they were in the first habituation trials [for each block, $p<.001$ ].

Thus, with regard to the end of habituation, increases of tone-evoked discharges were detectable as early as the first five trials of conditioning in both the $\mathrm{ACx}$ and the $\mathrm{BF}$. For the $\mathrm{ACx}$, this first increased responsiveness can be viewed as the expression of a dishabituatory process. The tone-evoked responses, which had strongly decreased across the habituation trials, returned toward the level they had in the first habituation trials; they increased above this level only later, during the subsequent blocks of conditioning trials. On the other hand, in the $\mathrm{BF}$, as early as the first five conditioning trials, reactivity to the tone was far above the level in the first habituation trials.

Extinction. The cortical responses evoked by the tone in the $80 \mathrm{msec}$ following tone onset showed a clear decrease across the eight blocks of the extinction procedure $[F(7,84)=3.038, p<.005]$. The responses at the end of extinction were similar to those observed in the first five trials of habituation $[F(1,12)<1]$, but they re- mained higher than those observed in the last five trials of habituation $[F(1,12)=11.206, p<.01]$. It is apparent from Figures 7 and 8 that this response decrement occurred rapidly after the US was removed. As early as the second block of extinction trials, the cortical responses were significantly lower than they were at the end of conditioning $[F(1,12)=18.241, p<.005]$. They were also decreased in the two subsequent blocks [in both cases, $p<.001]$. But, in the fifth and sixth blocks of extinction trials, which were given at the beginning of Day 3, the evoked responses expressed spontaneous recovery (see Figure 8): they were higher than they were in the last extinction block of Day 2 [respectively, $F(1,12)=7.536, p<.025$, and $F(1,12)=4.499, p<$ $.10]$, and they did not significantly differ from those at the end of conditioning [respectively, $F(1,12)=2.824$ and $F(1,12)=1.087$, n.s.]. Then, in the last two blocks, the responses again demonstrated extinction [with regard to the last conditioning block, respectively, $p<$ .005 , and $p<.001]$.

In the $\mathrm{BF}$ also, reactivity to the tone decreased across the eight blocks of extinction trials $[F(7,84)=4.676$, $p<.001]$. Nonetheless, in the last five extinction trials, reactivity to the tone remained higher than it was at the beginning $[F(1,12)=5.593, p<.05]$ and a fortiori at the end $[F(1,12)=10.042, p<.01]$ of habituation. Contrary to what was observed in the $\mathrm{ACx}$, only the

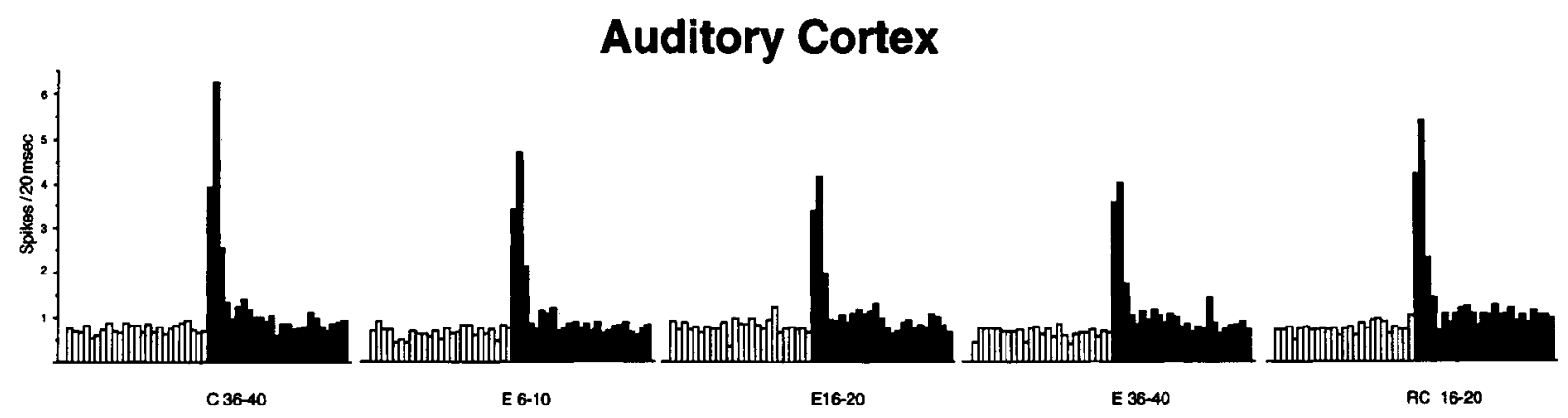

\section{Basal Forebrain}

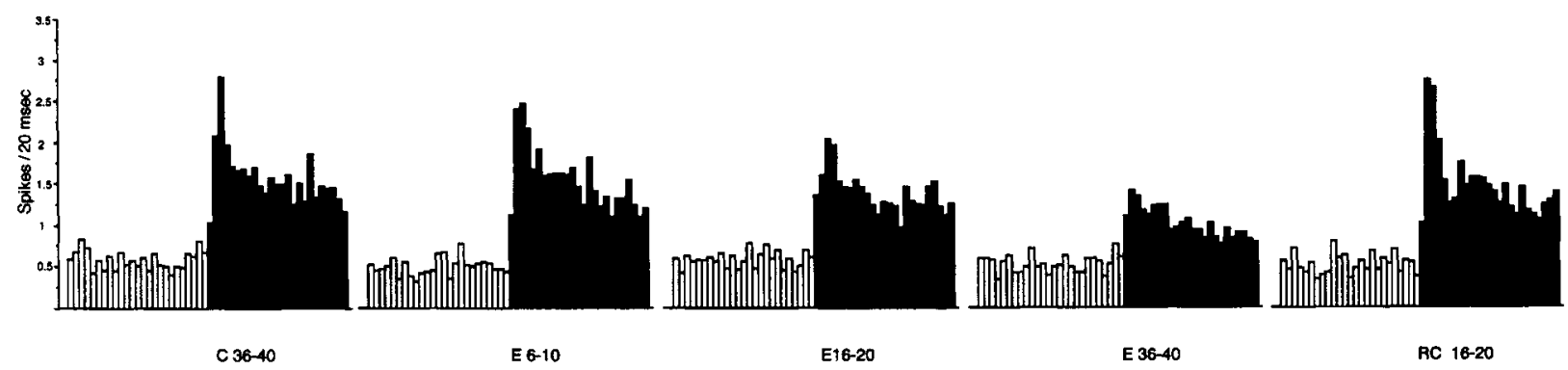

Figure 7. Extinction and reconditioning of the tone-evoked responses in auditory cortex and basal forebrain for the conditioned group. Each histogram represents the mean number of spikes per bin of 20 msec during the 500 msec preceding (open bars) and the 500 msec following (dark bars) tone onset. The histograms are from the last 5 conditioning trials (C36-40); from Trials 6-10, 16-20, and 36-40 of extinction (respectively, E6-10, E16-20, and E36-40); and from the last 5 reconditioning trials (RC16-20). Note the progressive extinction of the conditioned changes in both structures and their recurrence after 20 trials of reconditioning. Note also the decrease of the cortical tone-evoked response at the second block of extinction (E6-10), while the neuronal activity in the basal forebrain was unchanged yet. 

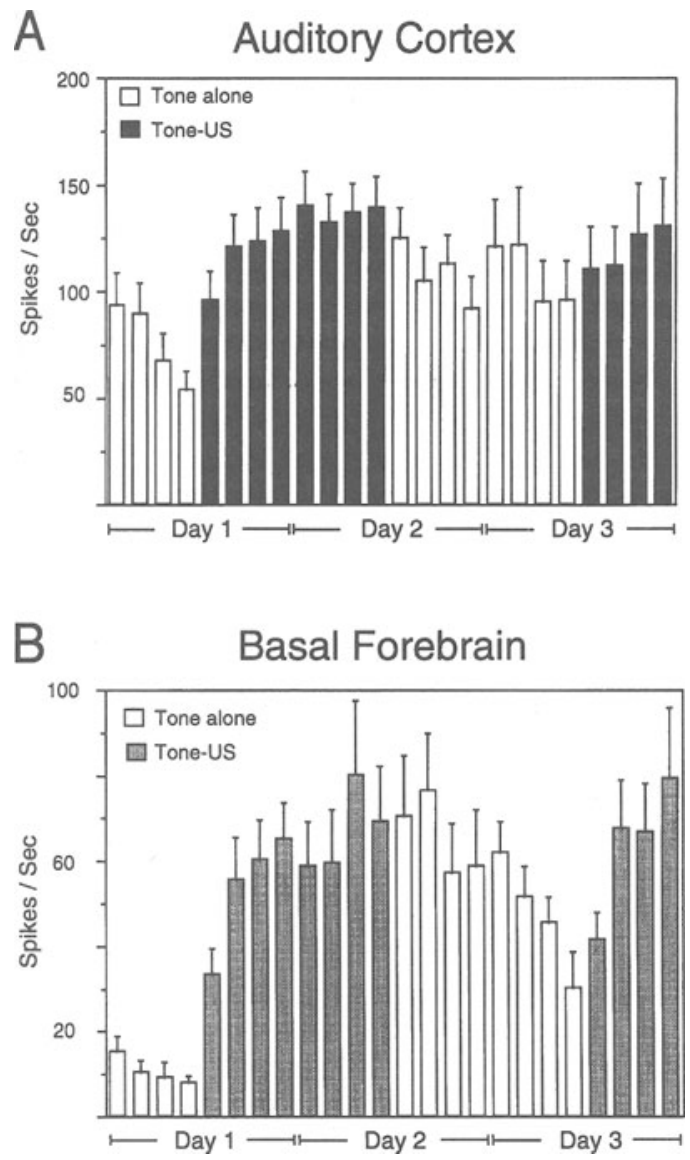

Figure 8. Evolution by blocks of 5 trials of the evoked responses occurring during the first $80 \mathrm{msec}$ of tone in auditory cortex and basal forebrain for the conditioned group. In the cortex, note that, after a marked decrement during habituation, the responses in the first conditioning block returned to the level of the first habituation block. Note also that, after a rapid decline, the responses at the end of extinction returned to the level of the first habituation block. In the basal forebrain, note in contrast, (1) the first increase far above the habituation level, (2) the maintenance of the conditioned responses during the first 10 extinction trials, and (3) that at the end of extinction, the responses were still far above the habituation level.

evoked discharges observed in the last two blocks of extinction significantly differed from those observed at the end of conditioning [respectively, $F(1,12)=4.757, p<$ .05 , and $F(1,12)=8.344, p<.025$; for all the other blocks, $p>.10]$.

Further analyses confirmed that the response decrement developed less rapidly in the BF than in the ACx. Compared with the level at the end of conditioning, the decrease of responsiveness to the tone was less pronounced in the $\mathrm{BF}$ than in the $\mathrm{ACx}$ during the first 10 trials of extinction $[F(1,24)=8.547, p<.01]$ as well as during the 10 following ones $[F(1,24)=4.723, p<.05]$. There was no longer any difference for the last 20 trials $[F(1,24)<1$, in each case $]$.

Thus, in both the ACx and the BF, the tone-evoked responses demonstrated extinction. However, they extinguished more rapidly and more completely in the $\mathrm{ACx}$ than in the BF. A general view of the results is provided in Figure 8 , which shows the evolution of the toneevoked responses in the $\mathrm{ACx}$ and in the BF across the 24 blocks of five trials of the experiment.

\section{DISCUSSION}

The main results of the present experiment can be summarized as follows. In animals showing conditioned behavioral responses indexed by increased myographic activity, the association between a previously habituated tone and a slight footshock increased neurons' responsiveness to the tone in very few trials, both in the auditory cortex and in the basal forebrain. In the two structures, the neuronal conditioned responses extinguished (totally or partially) during nonreinforced presentations of the tone; then they increased again when the tone was reassociated with footshock. These changes were mostly associative in nature, since the pseudoconditioned animals exhibited much smaller changes of their toneevoked responses in both structures.

\section{Methodological Considerations}

Testing neuronal responsiveness to an acoustic stimulus over 3 days in unanesthetized and unrestrained animals could give rise to two obvious criticisms: (1) stimulus constancy cannot be achieved, and (2) there is no guarantee that the exact same populations of neurons were recorded over the 3 days. With regard to stimulus constancy, the fact that the neuronal changes (1) were different in the conditioned and in the pseudoconditioned animals and (2) did not show the same pattern in the $\mathrm{ACx}$ and in the $\mathrm{BF}$ indicates that these changes were not simply due to the variability of the acoustic input. With regard to the stability of the recordings, there is no absolute guarantee that the same neurons were recorded from day to day, but this is most likely the case within a given session. As is apparent from Figure 8, we observed within a same session either increased responsiveness (on Day 1 from habituation to conditioning, and on Day 3 from extinction to reconditioning), or decreased responsiveness (on Day 2 from conditioning to extinction). Such changes could hardly be accounted for in terms of gaining or losing neurons within a given recording session; rather, they reflected neuronal plasticity that developed according to the significance of the stimulus. In addition, the cortical responses obtained at the end of the extinction procedure were similar to those obtained in the first habituation trials, which suggests that, from day to day, there was a decent amount of stability of the neuronal recordings.

Also, it could be argued that increased neuronal responses recorded in a freely moving animal reflected some conditioned movements at CS presentation. Such a possibility has to be considered especially for the $\mathrm{BF}$, since its neurons increase their firing rate when the animal is moving (Buzsáki et al., 1988), but not for the $\mathrm{ACx}$, since movements lead to decreased cortical toneevoked responses (Brugge \& Merzenich, 1973; Carmel 
\& Starr, 1963; Galambos \& Rupert, 1959). In the present experiment, the myographic activities detected within the first $80 \mathrm{msec}$ of tone were not enhanced during learning. Only longer latency activities displayed conditioning. In addition, these conditioned myographic responses were not present during the first 10 conditioning trials, whereas both the $\mathrm{ACx}$ and the $\mathrm{BF}$ neurons already exhibited conditioned increased discharges. Therefore, the enhancement of the evoked responses observed in the BF during the first $80 \mathrm{msec}$ of the CS was not due to movement. This is supported by the fact that conditioned responses of BF neurons have been found in urethane-anesthetized rats (Pirch, 1993). Also, when primate NBM neurons are recorded during performance of various behavioral tasks, the phasic changes in firing that they show in anticipation of the reward are clearly dissociated from the movement of the animal (for details, see Richardson \& DeLong, 1991a; Wilson, 1991).

In the present study, the BF neurons already exhibited slight responses to the tone during habituation. Several physiological and anatomical considerations have to be made with regard to this finding. First, acoustically evoked potentials have already been described in the $\mathrm{BF}$ of freely moving rats (Bringmann \& Klingberg, 1990); and the noise of an air puff is enough to produce evoked responses in the primate NBM (Richardson \& DeLong, 1991b). Second, the latency of the BF evoked responses, about $15 \mathrm{msec}$, can be considered as surprisingly short for a structure that does not belong to the classical auditory pathway. In the model of Weinberger et al. (1990), the NBM is supposed to be activated by the central nucleus of the amygdala (ACE). However, the ACE does not receive acoustic information directly; both thalamic and cortical auditory inputs reach the lateral amygdaloid nucleus (AL) first (LeDoux, Farb, \& Ruggiero, 1990; Romanski \& LeDoux, 1993). Clugnet, LeDoux, and Morrison (1990) showed that electrical stimulation of the medial geniculate body evoked neuronal discharges in the AL with a mean onset latency of $6.7 \mathrm{msec}$. The use of higher intensity currents and longer pulse durations allowed observation of neuronal discharges in some parts of the ACE with a mean response latency of $9.8 \mathrm{msec}$. Using the same conditions as those here, we previously observed tone-evoked responses in the medial geniculate body at a mean latency of $7.3 \mathrm{msec}$ (Hennevin, Maho, Hars, \& Dutrieux, 1993). Consequently, in the very best case, tone-evoked responses cannot be expected in the ACE before $17 \mathrm{msec}$ after tone onset. In fact, while short-latency $(12-25 \mathrm{msec})$ tone-evoked responses have been observed in the AL, the only responses detected in the ACE have had considerably longer latencies (>100 msec) (Bordi, Ledoux, Clugnet, \& Pavlides, 1993). Therefore, it seems quite unlikely that the short-latency tone-evoked responses obtained in the $\mathrm{BF}$ in the present experiment can reflect inputs from the ACE. A more direct pathway has to be considered. As mentioned by Záborszky, Cullinan, and Braun (1991), neurons of the caudal NBM which project to the ACx receive afferents from the peripeduncular area (Arnault $\&$
Roger, 1987; Groves, 1988; B. E. Jones \& Cuello, 1989; E. G. Jones, Burton, Saper, \& Swanson, 1976). This area, located just below the anterior part of the ventral division of the rat auditory thalamus, receives input from the inferior colliculus (Arnault \& Roger, 1987; LeDoux, Ruggiero, Forest, Stornetta, \& Reis, 1987; LeDoux, Ruggiero, \& Reis, 1985), the major auditory station of the midbrain. This projection from the "adjunct" auditory system to the BF could account for the short-latency increased discharges evoked by the tone in the BF.

Finally, caution is required in considering that, in the present experiment, the BF recordings were exclusively from cholinergic cells projecting to the cortex. Indeed, the NBM neurons constitute a heterogeneous population, as is attested by anatomical (see, for review, Wainer \& Mesulam, 1990) and electrophysiological (AstonJones, Shaver, \& Dinan, 1984; Semba, Reiner, McGeer, \& Fibiger, 1989) data. For example, GABAergic neurons are co-distributed with cholinergic cells through the entire BF (Kosaka, Tanchi, \& Dahl, 1988; Nagai, McGeer, \& McGeer, 1983; Záborszky, Heimer, Eckenstein, \& Leranth, 1986). But, in the most caudal part of the NBM area, they are smaller and fewer than in the other parts of the BF (Gritti, Mainville, \& Jones, 1993). In addition, the NBM region in the rat is not well differentiated from adjacent neural structures. In the region from which we recorded, cholinergic neurons are interspersed with noncholinergic cells belonging to the extended amygdala system (Alheid \& Heimer, 1988). It is possible that some of our multiunit recordings represented, in part, the activity of these extended amygdala neurons. Nonetheless, the fact that more than $90 \%$ of the cortically projecting neurons arising from this region are cholinergic (Mesulam, Mufson, Wainer, \& Levey, 1983; Rye et al., 1984) and the fact that low-intensity electrical stimulation delivered through the recording electrodes was able to induce EEG desynchronization support the proposal that the recorded cells included mostly cortically projecting cholinergic neurons.

\section{Relations With Previous Studies}

At the cortical level, rapid conditioning of evoked discharges was already reported. Both multiunit data (Edeline, Neuenschwander-El Massioui, \& Dutrieux, 1990a, 1990b; Oleson, Ashe, \& Weinberger, 1975) and singleunit data (Diamond \& Weinberger, 1984, 1989; Weinberger, Hopkins, \& Diamond, 1984) have indicated increased cortical evoked responses as well as changes in neurons' receptive fields (Edeline et al., 1993) after few pairing trials between a tone and an aversive event. As observed here, pseudoconditioning procedure produced a lower percentage of changes (Kraus \& Disterhoft, 1982 ); and when the extinction procedure was performed, the conditioned changes regressed (Diamond \& Weinberger, 1989). Finally, Kraus and Disterhoft have already observed that conditioned changes of cortical evoked responses can occur as early as $11-20 \mathrm{msec}$ after the CS onset, which led them to the conclusion that plasticity in the $\mathrm{ACx}$ is evident in the earliest components of 
the tone-evoked response. Thus, the characteristics of cortical plasticity observed here are quite consistent with the results of previous studies.

At the level of the BF, the present data corroborated previous observations by Rigdon and Pirch (1986) and Pirch (1993) showing that BF neurons can exhibit conditioned responses. However, since their animals were extensively pretrained before the recording session, it cannot be determined from their data in how many trials the BF neurons can exhibit conditioned changes. In an early study, Linseman and Olds (1973) reported that some neurons recorded in the SI, in the GP, or within the internal capsule showed learning-related increases in activity. These changes occurred after 45 trials, before the behavioral response (a rough quantification of the approach toward the appetitive reward), which took about 100 trials to be conditioned. This slow emergence of neuronal and behavioral changes was likely due to the protocol used; $300 \mathrm{CS}$ and US unpaired presentations, serving as a control period, were given before conditioning. More recently, Whalen, Kapp, and Pascoe (1994) reported discriminative conditioned responses from rabbit NBM neurons after 96 trials of discrimination training between a $\mathrm{CS}+$ and a $\mathrm{CS}-$. These discriminative responses were strong enough to be maintained over the partial extinction procedure during which they were tested.

In the present experiment, conditioned changes in the BF occurred very rapidly, within the first 5 trials of conditioning. They preceded the conditioned behavioral response, indexed by myographic activity, which developed after only 10 trials. Such a characteristic is similar to what was reported for the noradrenergic neurons of the locus coeruleus (LC), which have also been implicated in cortical plasticity (Bear et al., 1983; Kasamatsu, Watanabe, Heggelund, \& Scholler, 1985; Sato, Fox, \& Daw, 1989) as well as in the neuronal substrates of arousal (Aston-Jones \& Bloom, 1981; Berridge \& Foote, 1991; Foote, Aston-Jones, \& Bloom, 1980). Indeed when LC neurons were recorded during aversive classical conditioning, they exhibited conditioned increased discharges which occurred after few trials of conditioning (Rasmussen \& Jacobs, 1986; Sara \& Segal, 1991). However, unlike the LC cells (Sara \& Segal, 1991), the BF neurons showed long-lasting increased responsiveness to the CS after the US had been introduced: even if their responses decreased during the extinction procedure, they remained much higher than they were during habituation. Thus, the neuronal changes in the BF could be viewed as conditioned arousal responses, which persist once a stimulus has acquired an aversive value. This interpretation is not very surprising for neurons considered as critical elements of the ascending activating system (Semba, 1991; Steriade \& Buzsáki, 1990). It is also in agreement with the findings of Richardson and DeLong (1991a), who showed that the neurons in the primate NBM area respond to any arousing stimulus, as well as with those of Whalen et al. (1994), who showed that during behavioral training the activity of NBM rab- bit neurons is negatively correlated with the amount of EEG delta waves.

\section{Relations Between BF Activity and Cortical Plasticity}

Comparing the neural changes induced by conditioning in the $\mathrm{BF}$ and in the $\mathrm{ACx}$ can provide some insights about the possible influence of the BF activity on the cortical plasticity occurring during learning. First, increased responsiveness above the level of the first habituation trials appeared in the BF as early as the first 5 conditioning trials. In the $\mathrm{ACx}$ also, the evoked response started to increase after very few trials, but during the first 5 trials, they only recovered the level they had at the beginning of habituation. Responses above this level occurred only later. From this, one could consider that the BF neurons expressed associatively induced changes faster than the cortical neurons: Nonetheless, since the response decrement during the habituation procedure was stronger at the cortical level, the apparent precession of the BF might simply be the consequence of a larger habituation of the cortical responses, which would have penalized the cortex for developing important changes in the early trials of conditioning. Therefore, the claim that the BF neurons react faster than the cortical ones to associative learning is questionable.

Second, during the extinction procedure, the cortical response (1) started to decrease while the activity in the BF was still very high (the first 10 trials of extinction on Day 2), and (2) they showed spontaneous recovery while the activity in the BF was decreasing (the first $10 \mathrm{ex}-$ tinction trials on Day 3). Thus, all the changes occurring in the $\mathrm{ACx}$ were not dependent on the $\mathrm{BF}$ neuron activity. However, that the precession of $\mathrm{BF}$ conditioned changes with regard to those in the $\mathrm{ACx}$ is not clear-cut, as well as that the cortical changes are not always linked with BF activity, does not preclude that the BF could influence cortical plasticity. The rapidity of BF neurons to express enhanced discharges during conditioning is compatible with the notion that early BF activation, by inducing increased $\mathrm{ACh}$ release, could promote the induction of cortical plasticity during learning.

The question then arises of when and how ACh could influence the cortical response. The absence of changes in spontaneous $\mathrm{BF}$ activity over conditioning suggests that there was no tonic input from the BF on the cortical neurons. On the other hand, increased discharges to tone presentations occurred at a longer latency after tone onset in the BF than in the ACx. These two findings indicate that the increase of the cortical response at a given trial was not due to enhanced input coming from the BF at that trial. Consequently, we have to assume that the putative effect of $\mathrm{BF}$ activation on the cortical response resulted from the sequence of events that took place on preceding trials.

The strong and sustained increases of $\mathrm{BF}$ discharges which occurred at CS presentations and most likely also-although not quantified here-at footshock presentations probably increased the amount of cortical ACh 
release at each trial. ${ }^{1}$ Since ACh increases the cell's excitability over a period of minutes (Krnjevic \& Phillis, 1963; McCormick \& Prince, 1986; Metherate et al., 1992; Woody, Swartz, \& Gruen, 1978), the incoming thalamic inputs occurring at the following trials would have benefited from enhanced cortical excitability. Precisely this type of scheme was proposed in the model of Weinberger et al. (1990), in which ACh is supposed to promote cortical plasticity by amplifying the excitatory effects of the MGm input onto the cortical cells.

In addition, from the present data, we can suspect that $\mathrm{ACh}$ was released while the cortical neurons were activated by the acoustic input. Indeed, the cortical toneevoked responses extended until $60 \mathrm{msec}$ after tone onset, and the conditioned changes in the BF were present as early as $20 \mathrm{msec}$ after tone onset. If we take into account the slow-velocity conduction of the BF neurons (Aston-Jones, Shaver, \& Dinan, 1985; Semba et al., 1989), there were about 30 msec during which ACh was present while the cortical cells were still depolarized by the sensory volley. This is particularly important, given that a number of studies done with iontophoretic applications of ACh (Metherate et al., 1987) or BF stimulations (Edeline, Hars, et al., 1994; Metherate \& Ashe, 1991; Rasmusson \& Dykes, 1988; Tremblay et al., 1990) have shown that optimal conditions for observing longlasting facilitation of the cortical sensory responses are provided when $\mathrm{ACh}$ is present as the thalamic inputs reach the postsynaptic cells. Even if no parametric study were ever carried out to determine whether a $30-\mathrm{msec}$ overlap was sufficient to induce long-lasting cortical plasticity, this co-activation of the cortical neurons by $\mathrm{ACh}$ and by the thalamic input during the very first conditioning trials probably provides favorable conditions for the emergence of cortical plasticity.

\section{Conclusion}

The basal forebrain cholinergic system has been implicated in many functions, including arousal (Buzsáki \& Gage, 1991; Richardson \& DeLong, 1991a; Semba, 1991), cortical plasticity (Ashe \& Weinberger, 1991; Dykes, Tremblay, Warren, \& Bear, 1991), and, although controversial, attention, learning, and memory (Collerton, 1986; Dekker, Connor, \& Thal, 1991; Dunnett, Everitt, \& Robbins, 1991; Fibiger, 1991; Olton \& Wenk, 1987; Woolf \& Butcher, 1991). This diversity probably reflects the fact that a neuromodulatory system cannot be assigned to a unique function. In the particular case of the BF, its role in learning processes can hardly be dissociated from its involvement in arousal. The increased discharges of the BF neurons observed at CS presentations, which obviously are arousing stimuli, can reflect conditioned arousal as well as the learned association between the CS and the US. From the present data, the $\mathrm{BF}$ conditioned changes have two main characteristics: (1) their rapid occurrence after few trials of conditioning and (2) their persistence during extinction. The fact that the BF neurons react as fast as, or even faster than, the cortical ones in the course of conditioning, and that they exhibit short-latency increases in firing rate to the $\mathrm{CS}$, supports the notion that they can provide adequate conditions for learning-induced cortical plasticity. On the other hand, the fact that the BF conditioned changes were resistant to the extinction procedure contrasts notably with the rapid extinction of the cortical conditioned changes. It therefore seems more logical to consider the BF neurons as an alerting system which reacts persistently to previously significant stimuli, and the cortical neurons as a highly adaptative system which exhibits plasticity each time there is a change in stimulus significance.

\section{REFERENCES}

Alheid, G. F., \& Heimer, L. (1988). New perspectives in basal forebrain organization of special relevance for neuropsychiatric disorders: The striatopallidal, amygdaloid and corticopetal components of the substancia innominata. Neuroscience, 27, 1-39.

Arnault, P., \& Roger, M. (1987). The connections of the peripeduncular area studied by retrograde and anterograde transport in the rat. Journal of Comparative Neurology, 258, 463-476.

ASHE, J. H., \& WEINBERGER, N. M. (1991). Acetylcholine modulation of cellular excitability via muscarinic receptors: Functional plasticity in auditory cortex. In R. T. Richardson (Ed.), Activation to acquisition: Functional aspects of the basal forebrain cholinergic system (pp. 189-246). Boston: Birkhauser.

Aston-JONEs, G., \& BloOM, F. E. (1981). Norepinephrine-containing locus coeruleus neurons in behaving rats exhibit pronounced responses to non-noxious environmental stimuli. Journal of Neuroscience, 1, 887-900.

Aston-Jones, G., Shaver, R., \& Dinan, T. (1984). Cortically projecting nucleus basalis neurons are physiologically heterogeneous. Neuroscience Letters, 46, 19-24.

Aston-Jones, G., Shaver, R., \& Dinan, T. G. (1985). Nucleus basalis neurons exhibit axonal branching with decreased impulse conduction velocity in rat cerebrocortex. Brain Research, 325, 271-285.

BAKIN, J. S., \& WEINBERGER, N. M. (1990). Classical conditioning induces CS-specific receptive field plasticity in the auditory cortex of the guinea pig. Brain Research, 536, 271-286.

Bear, M. F., Paradiso, M. A., Schwartz, M., Nelson, S. B., Carnes, K. M., \& DANIELS, J. D. (1983). Two methods of catecholamine depletion in kitten visual cortex yield different effects on plasticity. Nature, 302, 245-247.

Belardetti, F., Borgia, R., \& Mancia, M. (1977). Prosencephalic mechanisms of EEG desynchronization in cerveau isolé cats. Electroencephalographic \& Clinical Neurophysiology, 42, 213-225.

BERRIDGE, C. W., \& Foote, S. L. (1991). Effects of locus coeruleus activation on electroencephalographic activity in neocortex and hippocampus. Journal of Neuroscience, 11, 3135-3145.

Bigl, V., Woolf, N. J., \& Butcher, L. L. (1982). Cholinergic projections from the basal forebrain to frontal, parietal, temporal, occipital and cingulate cortices: A combined fluorescent tracer and acetylcholinesterase analysis. Brain Research Bulletin, 8, 727-749.

Bordi, F., Ledoux, J. E., Clugnet, M. C., \& Pavlides, C. (1993). Single-unit activity in the lateral nucleus of the amygdala and overlying areas of the striatum in freely behaving rats: Rates discharge patterns and responses to acoustic stimuli. Behavioral Neuroscience, 107, 757-769.

BringmanN, A., \& Klingberg, F. (1990). Acoustically evoked potentials of the basal forebrain and nucleus cuneiformis of the freely moving rat. Biomedical \& Biochemical Acta, 49, 1147-1154.

BrugGe, J. F., \& MERz.ENICH, M. M. (1973). Responses of neurons in auditory cortex of macaque monkey to monaural and binaural stimulation. Journal of Neurophysiology, 36, 1130-1158.

Buzsáki, G., Bickford, R., PonomarefF, G., Thal, L. J., Mandel, R., \& GAGE, F. H. (1988). Nucleus basalis and thalamic control of neocortical activity in the freely moving rat. Journal of Neuroscience, 8, 4007-4026. 
BUZSÁKI, G., \& GAGE, F. H. (1991). Role of the basal forebrain cholinergic system in cortical activation and arousal. In R. T. Richardson (Ed.), Activation to acquisition: Functional aspects of the basal forebrain cholinergic system (pp. 115-133). Boston: Birkhauser.

CARMEL, P. W., \& STARR, A. (1963). Acoustical and nonacoustical factors modifying middle ear muscle activity in waking cats. Journal of Neurophysiology, 26, 598-616.

Casamenti, F., Deffenu, G., Abbamondi, A. L., \& Pepeu, G. (1986). Changes in cortical acetylcholine output induced by modulation of the nucleus basalis. Brain Research Bulletin, 16, 689-695.

Clugnet, C., LeDoux, J. E., \& Morrison, S. F. (1990). Unit responses evoked in the amygdala and striatum by electrical stimulation of the medial geniculate body. Journal of Neuroscience, 10, 1055-1061

Collerton, D. (1986). Cholinergic function and intellectual decline in Alzheimer's disease. Neuroscience, 19, 1-28.

Dekker, A. D. J. M., Connor, D. J., \& Thal, L. J. (1991). The role of cholinergic projections from the nucleus basalis in memory. Neuroscience \& Biobehavioral Reviews, 15, 299-317.

Delacour, J., Houcine, O., \& Costa, J. C. (1990). Evidence for a cholinergic mechanism of "learned" changes in the responses of barrel field neurons of the awake and undrugged rat. Neuroscience, 34, 1-8.

DeLoNG, M. R. (1971). Activity of pallidal neurons during movement. Journal of Neurophysiology, 43, 414-427.

DÉTÁri, L., \& VANDERWOLF, C. H. (1987). Activity of identified cortically projecting and other basal forebrain neurons during slowwaves and cortical activation in anaesthetized rats. Brain Research, 437, 1-8.

Diamond, D. M., \& Weinberger, N. M. (1984). Physiological plasticity of single neurons in auditory cortex of cat during acquisition of the pupillary conditioned response: II. Secondary field (AII). Behaviioral Neuroscience, 98, 189-210.

Diamond, D. M., \& Weinberger, N. M. (1986). Classical conditioning rapidly induces specific changes in frequency receptive fields of single neurons in secondary and ventral ectosylvian auditory cortical fields. Brain Research, 372, 357-360.

DiAmond, D. M., \& Weinberger, N. M. (1989). Role of context in the expression of learning-induced plasticity of single neurons in auditory cortex. Behavioral Neuroscience, 103, 471-494.

Dunnett, S. B., Everitt, B. J., \& Robiins, T. W. (1991). The basal forebrain-cortical cholinergic system: Interpreting the functional consequence of excitotoxic lesion. Trends in Neurosciences, 14, 494-501

Dykes, R. W., Tremblay, N., Warren, R. A., \& Bear, M. F. (1991). Cholinergic modulation of synaptic plasticity in the sensory neocortex. In R. T. Richardson (Ed.), Activation to acquisition: Functional aspects of the basal forebrain cholinergic system (pp. 325345). Boston: Birkhauser.

Edeline, J.-M., Hars, B., Maho, C., \& Hennevin, E. (1994). Transient and prolonged facilitation of tone-evoked responses induced by basal forebrain stimulation in the rat auditory cortex. Experimental Brain Research, 97, 373-386.

Edeline, J.-M., Maho, C., Hars, B., \& Hennevin, E. (1994). Nonawaking basal forebrain stimulation enhances auditory cortex responsiveness during slow-wave sleep. Brain Research, 636, 333337.

Edeline, J.-M., Neuenschwander-El Massioui, N., \& Dutrieux, G. (1990a). Discriminative long-term retention of rapidly induced multiunit changes in the hippocampus, medial geniculate and auditory cortex. Behavioral Brain Research, 39, 145-155.

Edeline, J.-M., Neuenschwander-El Massioui, N., \& Dutrieux, G. (1990b). Frequency-specific cellular changes in the auditory system during acquisition and reversal of discriminative conditioning. Psychobiology, 18, 382-393.

Edeline, J.-M., Pham, P., \& Weinberger, N. M. (1993). Rapid development of learning-induced receptive field plasticity in the auditory cortex. Behavioral Neuroscience, 107, 539-551.

Edeline, J.-M., \& Weinberger, N. M. (1993). Receptive field plasticity in the auditory cortex during frequency discrimination training: Selective retuning independent of task difficulty. Behavioral Neuroscience, 107, 82-103.
FIBIGER, H. C. (1991). Cholinergic mechanisms in learning, memory and dementia: A review of recent evidences. Trends in Neurosciences, 14, 220-223.

Foote, S. L., Aston-Jones, G., \& Bloom, F. E. (1980). Impulse activity of locus coeruleus neurons in awake rats and monkey is a function of sensory stimulation and arousal. Proceedings of the $\mathrm{Na}$ tional Academy of Sciences, 77, 3033-3037.

Galambos, R., \& RuPERT, A. (1959). Action of middle ear muscles in normal cats. Journal of the Acoustical Society of America, 31, 349355

Gonzalez-Lima, F., \& Scheich, H. (1986). Neural substrates for tone-conditioned bradycardia demonstrated with 2 deoxyglucose II: Auditory cortex plasticity. Behavioral Brain Research, 20, 281-293.

Gritti, I., Mainville, L., \& Jones, B. E. (1993). Codistribution of GABA- with acetylcholine-synthesizing neurons in the basal forebrain of the rat. Journal of Comparative Neurology, 329, 438-457.

Groves, E. A. (1988). Neural associations of the substantia innominata in the rat: Afferent connections. Journal of Comparative Neurology, 277, 315-346.

Hars, B., Maho, C., Edeline, J.-M., \& Hennevin, E. (1993). Basal forebrain stimulation facilitates tone-evoked responses in the auditory cortex of awake rat. Neuroscience, 56, 61-74

Hennevin, E., Maho, C., Hars, B., \& Dutrieux, G. (1993). Learninginduced plasticity in the medial geniculate nucleus is expressed during paradoxical sleep. Behavioral Neuroscience, 107, 1018-1030.

Jenkins, W. M., Merzenich, M., Ochs, M. T., Allard, T., \& GuicRoBLES, E. (1990). Functional reorganization of primary somatosensory cortex in adult owl monkeys after behaviorally controlled tactile stimulation. Journal of Neurophysiology, 63, 82-104.

JoNes, B. E., \& CuELLo, A. C. (1989). Afferents to the basal forebrain cholinergic cell area from pontomesencephalic-catecholamine, serotonin and acetylcholine-neurons. Neuroscience, 31, 37-61.

Jones, E. G., Burton, H., Saper, C. B., \& Swanson, L. W. (1976). Midbrain, diencephalic and cortical relationships of the basal nucleus of Meynert and associated structures in primates. Journal of Comparative Neurology, 167, 385-420.

Kasamatsu, T., Watanabe, K., Heggelund, P., \& Scholler, E. (1985). Plasticity in cat visual cortex restored by electrical stimulation of the locus coeruleus. Neuroscience Research, 2, 365-386.

KosaKa, T., TANCHI, M., \& DAHL, J. L. (1988). Cholinergic neurons containing GABA-like and/or glutamic acid decarboxylase-like immunoreactivity in various brain regions of the rat. Experimental Brain Research, 70, 605-617.

Kraus, N., \& Disterhoft, J. F. (1982). Response plasticity of single neurons in rabbit auditory association cortex during tone-signalled learning. Brain Research, 246, 205-215.

Krnjevic, K., \& Phillis, J. W. (1963). Pharmacological properties of acetylcholine sensitive cells in the cerebral cortex. Journal of Physiology, 166, 328-350.

Lamour, Y., DUtar, P., \& JOBERT, A. (1982). Topographic organization of basal forebrain neurons projecting to the rat cerebral cortex. Neuroscience Letters, 34, 117-122.

Lamour, Y., Dutar, P., JoberT, A., \& Dykes, R. W. (1988). An iontophoretic study of single somatosensory neurons in rat granular cortex serving the limb: A laminar analysis of glutamate and acetylcholine effects on receptive field properties. Journal of Neurophysiology, 60, 725-750.

Lamour, Y., Dutar, P., Rascol, O., \& JoberT, A. (1986). Basal forebrain neurons projecting to the rat frontoparietal cortex: Electrophysiological and pharmacological properties. Brain Research, 362, $122-131$.

LebeauX, M. O., LéPIne, D., \& Rouanet, H. (1975). Analyse des comparaisons-Programme VAR3-Structure $S\langle G\rangle{ }^{*} T$ [Computer software]. Paris.

LeDoux, J. E., Farb, C., \& Ruggiero, D. A. (1990). Topographic organization of neurons in the acoustic thalamus that project to the amygdala. Journal of Neuroscience, 10, 1043-1054.

LeDoux, J. E., Ruggiero, D. A., Forest, R., Stornetta, R., \& Reis, D. J. (1987). Topographic organization of convergent projections to the thalamus from the inferior colliculus and spinal cord in the rat. Journal of Comparative Neurology, 264, 123-146.

LeDoux, J. E., Ruggiero, D. A., \& Reis, D. J. (1985). Projections to 
the subcortical forebrain from anatomically defined regions of the medial geniculate body in the rat. Journal of Comparative Neurology, 242, 182-213.

Linseman, M. A., \& Olds, J. (1973). Activity changes in rat hypothalamus, preoptic area, and striatum associated with Pavlovian conditioning. Journal of Neurophysiology, 36, 1038-1050.

Luiten, P. G. M., Gaykema, R. P. A., Traber, I., \& Spencer, D. G. J. (1987). Cortical projection patterns of magnocellular basal nucleus subdivisions as revealed by anterograde transported phaseolus vulgaris leucoagglutinin. Brain Research, 413, 229-250.

MCCORMICK, D. A., \& PRINCE, D. A. (1986). Mechanisms of action of acetylcholine in the guinea pig cerebral cortex, in vitro. Journal of Physiology, 375, 169-194.

Mesulam, M. M., Mufson, E. J., Wainer, B. H., \& Levey, A. I. (1983). Central cholinergic pathways in the rat: An overview based on an alternative nomenclature (Ch1-Ch6). Neuroscience, 10, 1185 1201.

Metherate, R., \& Ashe, J. H. (1991). Basal forebrain stimulation modifies auditory cortex responsiveness by an action at muscarinic receptors. Brain Research, 559, 163-167.

Metherate, R., Cox, C. L., \& Ashe, J. H. (1992). Cellular bases of neocortical activation: Modulation of neural oscillation by the nucleus basalis and endogenous acetylcholine. Journal of Neuroscience, 12, 4701-4711.

Metherate, R., Tremblay, N., \& Dykes, R. W. (1987). Acetylcholine permits long-term enhancement of neuronal responsiveness in cat primary somatosensory cortex. Neuroscience, 22, 75-81.

Metherate, R., Tremblay, N., \& Dykes, R. W. (1988). Transient and prolonged effects of acetylcholine on responsiveness of cat somatosensory cortical neurons. Journal of Neurophysiology, 59, 1253-1275.

MorA, F., Rolls, E. T., \& Burton, M. J. (1976). Modulation during learning of the responses of neurons in the lateral hypothalamus to the sight of food. Experimental Neurology, 53, 508-519.

Morizumi, T., \& HatTori, T. (1992). Separate neuronal populations of the rat globus pallidus projecting to the subthalamic nucleus, auditory cortex and pedunculopontine tegmental area. Neuroscience, 46, 701-710.

MurPhy, P. C., \& Sillito, A. M. (1991). Cholinergic enhancement of direction selectivity in the visual cortex of the cat. Neuroscience, $\mathbf{4 0}$, 13-20.

NaGal, T., McGeer, P. L., \& McGeer, E. G. (1983). Distribution of GABA-T intensive neurons in the rat forebrain and midbrain. Journal of Comparative Neurology, 218, 220-238.

Oleson, T., Ashe, J., \& Weinberger, N. M. (1975). Modification of auditory and somatosensory activity during pupillary conditioning in the paralyzed cat. Journal of Neurophysiology, 38, 1114-1139.

OLTON, D. S., \& WENK, G. L. (1987). Dementia: Animal models of the cognitive impairments produced by degeneration of the basal forebrain cholinergic system. In H. Y. Meltzer (Ed.), Psychopharmacology: The third generation of progress (pp. 941-953). New York: Raven Press

Paxinos, G., \& Watson, C. (1986). The rat brain in stereotaxic coordinates. New York: Academic Press.

Pirch, J. H. (1993). Basal forebrain and frontal cortex neuron responses during visual discrimination in the rat. Brain Research Bulletin, 31, 78-83.

Pirch, J. H., Corbus, M. J., Rigdon, G. C., \& Lyness, W. H. (1986). Generation of cortical event-related slow potentials in the rat involves nucleus basalis cholinergic innervation. Electroencephalographic \& Clinical Neurophysiology, 63, 464-475.

RASMUSSEN, K., \& JACOBS, B. L. (1986). Single unit activity of the locus coeruleus neurons in the freely moving cat: II. Conditioning and pharmacological studies. Brain Research, 371, 335-344.

Rasmusson, D. D., \& DYKEs, R. W. (1988). Long-term enhancement of evoked potentials in cat somatosensory cortex produced by coactivation of basal forebrain and cutaneous receptors. Experimental Brain Research, 70, 276-286.

Recanzone, G. H., Merzenich, M. M., Jenkins, W. M., Grajski, K. A., \& Dinse, H. A. (1992). Topographic reorganization of the hand representation in cortical area $3 \mathrm{~b}$ of owl monkeys trained in a frequency discrimination task. Journal of Neurophysiology, 67, $1031-1056$.

Recanzone, G. H., Schreiner, C. E., \& Merzenich, M. (1993). Plasticity in the frequency representation of primary auditory cortex following discrimination training in adult owl monkeys. Journal of Neuroscience, 13, 87-103.

Richardson, R. T., \& DELong, M. R. (1986). Nucleus basalis of Meynert neuronal activity during a delayed response task in monkey. Brain Research, 399, 364-368.

Richardson, R. T., \& DeLong, M. R. (1991a). Electrophysiological studies of the function of the nucleus basalis in primates. In T. C. Napier, P. W. Kavilas, \& I. Hanin (Eds.), The basal forebrain: Anatomy to function (pp. 233-252). New York: Plenum.

Richardson, R. T., \& DELong, M. R. (199lb). Functional implication of tonic and phasic changes in nucleus basalis neurons. In R. T. Richardson (Ed.), Activation to acquisition: Functional aspects of the basal forebrain cholinergic system (pp. 135-166). Boston: Birkhauser.

Rigdon, G. C., \& PIRCH, J. H. (1986). Nucleus basalis involvement in conditioned neuronal responses in the rat frontal cortex. Journal of Neuroscience, 6, 2535-2542.

Rolls, E. T., Sanghera, M. K., \& Roper-Hall, A. (1979). The latency of activation of neurones in the lateral hypothalamus and substantia innominata during feeding in the monkey. Brain Research, 164, 121-135.

ROMANSKI, L. M., \& LEDOUX, J. E. (1993). Information cascade from primary auditory cortex to the amygdala: Corticocortical and corticoamygdaloid projections of temporal cortex in the rat. Cerebral Cortex, 3, 515-532.

Rye, D. B., Wainer, B. H., Mesulam, M. M., Mufson, E. J., \& Saper, C. B. (1984). Cortical projections arising from the basal forebrain: A study of cholinergic and noncholinergic components employing combined retrograde tracing and immunohistochemical localization of choline acetyltransferase. Neuroscience, 3, 627-643.

SAPER, C. B. (1984). Organization of cerebral cortical afferent systems in the rat: II. Magnocellular basal nucleus. Journal of Comparative Neurology, 222, 313-342.

Sara, S. J., \& SEgal, M. (1991). Plasticity of sensory responses of locus coeruleus neurons in the behaving rat: Implication for cognition. In C. D. Barnes \& O. Pompeiano (Eds.), Progress in brain research (Vol. 88, pp. 571-585). Amsterdam: Elsevier.

SATo, H., Fox, K., \& DAW, N. (1989). Effect of electrical stimulation of locus coeruleus on the activity of neurons in the cat visual cortex. Journal of Neurophysiology, 62, 946-958.

SCHEICH, H., \& SIMONIS, C. (1991). Conditioning changes frequency representation in gerbil auditory cortex. Society for Neuroscience Abstracts, 17, 450 .

SEMBA, K. (1991). The cholinergic basal forebrain: A critical role in cortical arousal. In T. C. Napier, P. W. Kavilas, \& I. Hanin (Eds.), The basal forebrain: Anatomy to function (pp. 197-218). New York: Plenum.

Semba, K., Reiner, P. B., McGeér, E. G., \& Fibiger, H. C. (1989). Brainstem projecting neurons in the rat basal forebrain: Neurochemical, topographical, and physiological distinction from cortically projecting cholinergic neurons. Brain Research Bulletin, 22, 501-509.

Sillito, A., \& KEMP, J. A. (1983). Cholinergic modulation of the functional organization of the cat visual cortex. Brain Research, 289, 143-155.

STERIAde, M., \& Buzsíki, G. (1990). Parallel activation of thalamic and cortical neurons by brainstem and basal forebrain cholinergic system. In M. Steriade \& D. Biesold (Eds.), Brain cholinergic systems (pp. 3-62). Oxford: Oxford University Press.

Travis, R. P., \& Sparks, D. L. (1968). Unitary responses and discrimination learning in the squirrel monkey: The globus pallidus. Physiology \& Behavior, 3, 187-196.

Tremblay, N., WARREN, R. A., \& Dykes, R. W. (1990). Electrophysiological studies of acetylcholine and the role of the basal forebrain in the somatosensory cortex of the cat: II. Cortical neurons excited by somatic stimuli. Journal of Neurophysiology, 64, 1212-1222. Wainer, B. H., \& Mesulam, M. M. (1990). Ascending cholinergic 
pathways in the rat brain. In M. Steriade \& D. Biesold (Eds.), Brain cholinergic systems (pp. 65-119). Oxford: Oxford University Press. Weinberger, N. M., Ashe, J. H., Metherate, R., McKenna, T. M. DiAMOND, D. M., \& BAKIN, J. (1990). Retuning auditory cortex by learning: A preliminary model of receptive field plasticity. Concepts in Neuroscience, 1, 91-132.

Weinberger, N. M., \& Diamond, D. M. (1987). Physiological plasticity in auditory cortex: Rapid induction by learning. Progress in Neurobiology, 29, 1-55.

Weinberger, N. M., Hopkins, W., \& Diamond, D. M. (1984). Physiological plasticity of single neurons in auditory cortex of cat during acquisition of the pupillary conditioned response: I. Primary field (AI). Behavioral Neuroscience, 98, 171-188.

Whalen, P. J., KAPP, B. S., \& PASCOE, J. P. (1994). Neuronal activity within the nucleus basalis and conditioned neocortical electroencephalographic activation. Journal of Neuroscience, 14, 1623-1633.

WILSON, F. A. W. (1991). The relationship between learning, memory and neuronal responses in the primate basal forebrain. In T. C. Napier, P. W. Kavilas, \& I. Hanin (Eds.), The basal forebrain: Anatomy to function (pp. 253-266). New York: Plenum.

WILsON, F. A. W., \& Rolls, E. T. (1990a). Learning and memory is reflected in the responses of reinforcement-related in the primate basal forebrain. Journal of Neuroscience, 10, 1254-1267.

Wilson, F. A. W., \& Rolls, E. T. (1990b). Neuronal responses related to reinforcement in the primate basal forebrain. Brain Research, 509, 213-231.
Woody, C. D., SWartZ, B. E., \& Gruen, E. (1978). Effects of acetylcholine and cyclic GMP on input resistance of cortical neurons in awake cats. Brain Research, 158, 373-395.

WOOLF, N. J., \& BUTCHER, L. L. (1991). The cholinergic basal forebrain as a cognitive machine. In R. T. Richardson (Ed.), Activation to acquisition: Functional aspects of the basal forebrain cholinergic system (pp. 347-380). Boston: Birkhauser

Záborszky, L., Cullinan, W. E., \& Braun, A. (1991). Afferents to basal forebrain cholinergic projection neurons: An update. In T. C. Napier, P. W. Kavilas, \& I. Hanin (Eds.), The basal forebrain: Anatomy to function (pp. 43-100). New York: Plenum.

Záborszky, L., Heimer, L., Eckenstein, F., \& Leranth, C. (1986). GABAergic input to cholinergic forebrain neurons: An ultrastructural study using retrograde tracing of HRP and double immunolabeling. Journal of Comparative Neurology, 250, 282-295.

\section{NOTE}

1. NBM neurons were shown to increase discharges in response to noxious stimuli even in anesthetized animals (Aston-Jones, Shaver, \& Dinan, 1985; Détári \& Vanderwolf, 1987; Lamour, Dutar, Rascol, \& Jobert, 1986).

(Manuscript received August 2, 1994; revision accepted for publication October 12, 1994.) 